\title{
Nucleus size and DNA accessibility are linked to the regulation of paraspeckle formation in cellular differentiation
}

\author{
Markus Grosch', Sebastian Ittermann ${ }^{1}$, Ejona Rusha ${ }^{2}$, Tobias Greisle ${ }^{1}$, Chaido Ori ${ }^{1,3}$, Dong-Jiunn Jeffery Truong ${ }^{4}$, \\ Adam C. O'Neill', Anna Pertek ${ }^{2}$, Gil Gregor Westmeyer ${ }^{4}$ and Micha Drukker ${ }^{1,2^{*}}$
}

\begin{abstract}
Background: Many long noncoding RNAs (IncRNAs) have been implicated in general and cell type-specific molecular regulation. Here, we asked what underlies the fundamental basis for the seemingly random appearance of nuclear IncRNA condensates in cells, and we sought compounds that can promote the disintegration of IncRNA condensates in vivo.

Results: As a basis for comparing IncRNAs and cellular properties among different cell types, we screened IncRNAs in human pluripotent stem cells (hPSCs) that were differentiated to an atlas of cell lineages. We found that paraspeckles, which form by aggregation of the IncRNA NEAT1, are scaled by the size of the nucleus, and that small DNA-binding molecules promote the disintegration of paraspeckles and other IncRNA condensates. Furthermore, we found that paraspeckles regulate the differentiation of hPSCs.

Conclusions: Positive correlation between the size of the nucleus and the number of paraspeckles exist in numerous types of human cells. The tethering and structure of paraspeckles, as well as other IncRNAs, to the genome can be disrupted by small molecules that intercalate in DNA. The structure-function relationship of IncRNAs that regulates stem cell differentiation is likely to be determined by the dynamics of nucleus size and binding site accessibility.
\end{abstract}

\section{Background}

The human genome encodes for tens of thousands of lncRNAs [1], and we have just begun revealing their regulatory functions in development, disease, and homeostasis. Nuclear IncRNAs have been implicated in the regulation of gene expression in diverse ways, including the recruitment of chromatin-remodeling complexes of the SWI/SNF family [2], and interaction with Polycomb repressive complexes which modify histones [3]. Importantly, many nuclear

\footnotetext{
* Correspondence: micha.drukker@helmholtz-muenchen.de

'Institute of Stem Cell Research (ISF), Helmholtz Zentrum München, Neuherberg, Germany

${ }^{2}$ Institute of Stem Cell Research (ISF), iPSC Core Facility, Helmholtz Zentrum München, Neuherberg, Germany

Full list of author information is available at the end of the article
}

IncRNAs have been reported to reside in condensates, named collectively "membraneless compartments" [4]. A notable example are paraspeckles which comprise the lncRNA NEAT1 and RNA-binding proteins (RBPs) that influence gene expression by post-transcriptional regulation of splicing and polyadenylation [5, 6], as well as by interaction with the SWI/SNF complex that remodels nucleosomes [7]. Similarly, the IncRNA MALAT1, which also forms condensates, has been shown to regulate gene expression by interactions with splicing factors [8]. Despite advancements in understanding the composition and formation of IncRNAprotein condensates $[9,10]$ and separately the functions of RBPs, for example, TDP-43 in the regulation of alternative polyadenylation [11], the regulation mediated together by the

(c) The Author(s). 2020 Open Access This article is licensed under a Creative Commons Attribution 4.0 International License, which permits use, sharing, adaptation, distribution and reproduction in any medium or format, as long as you give appropriate credit to the original author(s) and the source, provide a link to the Creative Commons licence, and indicate if changes were made. The images or other third party material in this article are included in the article's Creative Commons licence, unless indicated otherwise in a credit line to the material. If material is not included in the article's Creative Commons licence and your intended use is not permitted by statutory regulation or exceeds the permitted use, you will need to obtain permission directly from the copyright holder. To view a copy of this licence, visit http://creativecommons.org/licenses/by/4.0/ The Creative Commons Public Domain Dedication waiver (http://creativecommons.org/publicdomain/zero/1.0/) applies to the data made available in this article, unless otherwise stated in a credit line to the data. 
aggregation of lncRNAs, RBPs, and other factors is still not well understood.

Nuclear lncRNAs, and presumably lncRNA condensates such as paraspeckles, can be tethered to doublestranded (ds) DNA by forming RNA-dsDNA triple helix complexes, and such interactions have been proposed to rely on sequence-specific base-pairing interactions [12, 13]. Whether such interactions are the basis for the locations of hundreds of associations with open chromatin regions, which were reported for IncRNAs such as NEAT1 and MALAT1, is an open question [14]. A strategy that could assist in elucidating the underlying mechanisms of interactions between lncRNAs and chromatin is the identification of compounds that alter the structure of dsDNA. Plausible types of small molecules in this regard include DNA-binding compounds from the Hoechst family [15], and a host of other minor grooveassociating molecules that are used for chemotherapy, such as actinomycin D (ActD) [16].

The use of hPSCs for studying the functions of lncRNA condensates is advantageous in several respects: first, the differentiation of hPSCs is accompanied by changes of genome architecture [17] that create opportunities to study the formation of lncRNA condensates in cell fate transitions, as we have shown recently for paraspeckles [18]. Second, differentiation protocols allow the generation of cell types from the three embryonic germ layers in order to analyze and compare general and cell type-specific regulation, for example, using differentiated neurons, hepatocytes, and cardiomyocytes. In this respect, we have recently observed that the number of paraspeckles exhibited by individual cells during early differentiation of mouse and human PSCs is variable despite the robustness of differentiation protocols in creating homogenous preparations of differentiated cells [18], and similar observations have been made previously in tumor cell lines [19]. This indicates that an unknown form of structural regulation causes the seemingly random appearance of paraspeckles in cells, which could be linked to general mechanisms that regulate the vastly different number of paraspeckles observed in different cell types and upon exit from pluripotency [18, 20,21].

Our objective here was to expand the understanding of the fundamental basis for formation of IncRNA-protein condensates and their functions. We first screened lncRNAs that were previously shown to concentrate in foci and used hPSC differentiation protocols of the three germ layers in order to characterize lncRNAs that exhibit dynamic expression patterns. This led us to analyze in detail the formation of NEAT1 condensates, namely paraspeckles, and to test whether small molecules can disintegrate them in vivo. In order to identify the intrinsic regulation of paraspeckles, we differentiated an atlas of cell types, and then applied dsDNA minor groove-associated small molecules. By doing so, we dissected the kinetics of paraspeckle formation in cellular differentiation and discovered that the amount of paraspeckles is scaled in relation to cells' nucleus size. We further validated the scaling principle using different human somatic cells, fibroblasts that underwent reprogramming, and murine cells. Moreover, we identified the first small molecules that disintegrate paraspeckles and other lncRNA condensates, presumably by perturbing RNA-dsDNA triple helix structures. Beyond the importance of these molecules for studying lncRNA condensates and their tethering to the chromatin, some of these small molecules are approved drugs for chemotherapy, which raises the possibility that they could be repurposed for treating diseases involving aberrant formation of IncRNA condensates. Finally, we demonstrated that paraspeckles are involved in the differentiation of hPSCs by slowing down the process. Thereby, we connected paraspeckles to nuclear scaling, DNA tethering, and developmental regulation and, more broadly, identified reagents for lncRNA condensate research and medicine.

\section{Results \\ Dynamics of nuclear IncRNAs in the differentiation of human PSCs}

To conduct an unbiased assessment of the association of cell types and developmental stages with the expression and condensation of nuclear lncRNAs, we differentiated human PSCs to numerous lineages (Fig. 1a). We first optimized the differentiation protocols of lateral mesoderm and mesenchymal stem cells (MSCs), definitive endoderm and lung progenitor cells, and neural stem cells (NSCs) and cortical neuron progenitors, which represented, respectively, early and late stages of differentiation of the three germ layers mesoderm, endoderm, and ectoderm. We observed the upregulation of lateral mesoderm markers MESP1, T (Brachyury), FZD4, and MIXL1, and transcription factors TWIST and SLUG which regulate the epithelial-to-mesenchymal transition of MSCs, as well as surface markers that are characteristic for MSCs (Fig. 1b and Additional file 1: Figure S1a). When differentiated to definitive endoderm, we detected the upregulation of $S O X 17, F O X A 2$, surface markers CXCR4, CD117, and EPCAM, and later of the master lung transcription factor $N K X 2.1$ (Fig. 1c and Additional file 1: Figure S1b-d). Moreover, the upregulation of PAX6, SOX1, ASCL1, NESTIN, and FOXG1 mRNAs and respective proteins confirmed the differentiation to NSCs and cortical neuron progenitors, respectively (Fig. 1d and Additional file 1: Figure S1e, f). Finally, in all cell types, we observed the downregulation of the pluripotency factors OCT4, SOX2, and NANOG (Fig. 1b-d), which confirmed their differentiation. 


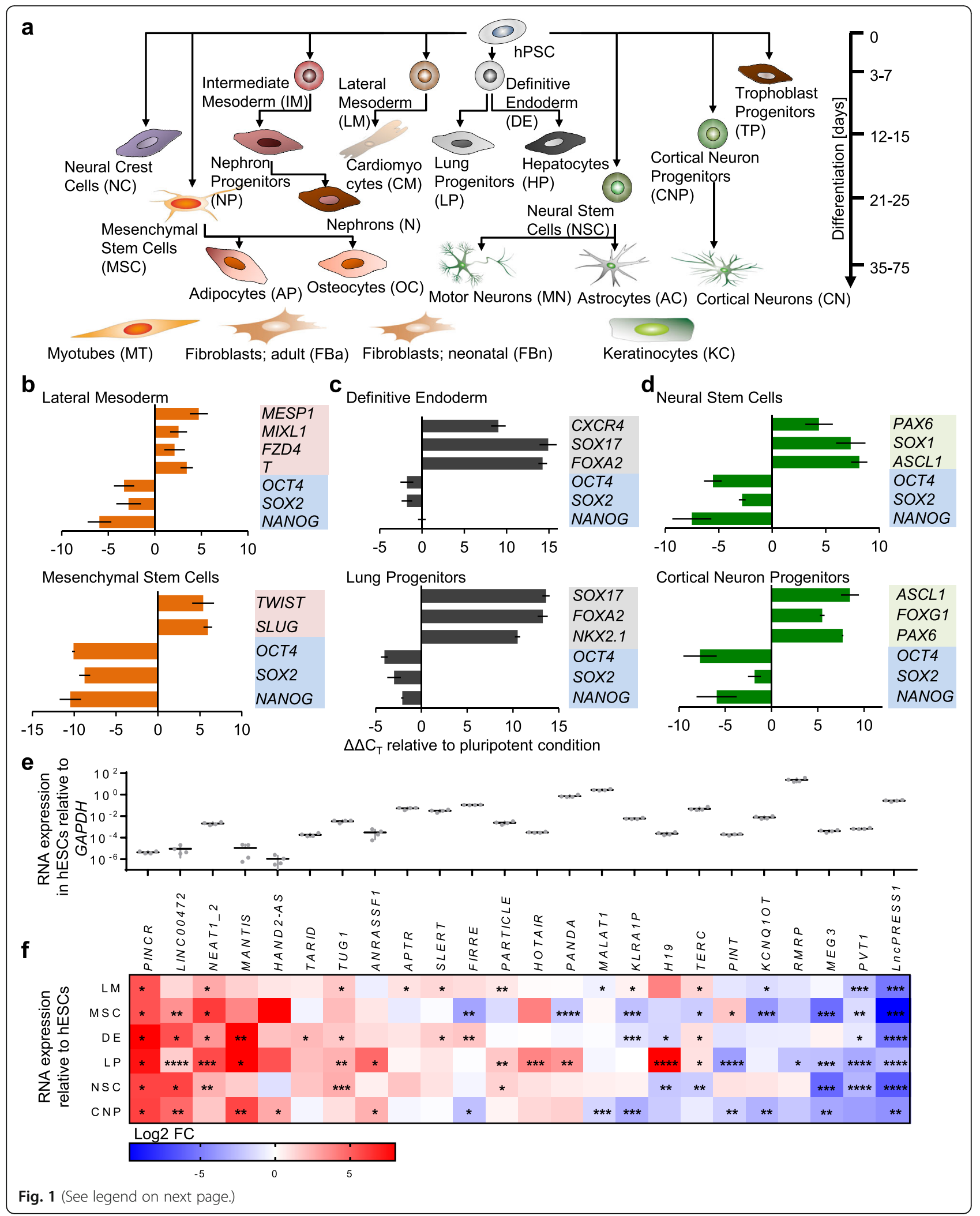


(See figure on previous page.)

Fig. 1 Characterization of developmentally regulated IncRNAs. a A scheme illustrating the cell types that were produced in this study by differentiation of hPSCs. Starting with undifferentiated cells at the top, hPSCs were differentiated to precursors of the germ layers, embryonic and extraembryonic progenitors, and terminally differentiated cells. The lineage and approximate developmental distance was estimated based on the expression of developmental markers as outlined below and in Additional file 1: Figure S1. In addition, primary preparations of keratinocytes, fibroblasts (adult and neonatal origin), and myotubes were analyzed. b-d RT-qPCR analysis of selected lineage markers corresponding to lateral mesoderm, and mesenchymal stem cells (b); definitive endoderm and lung progenitors (c); and neural progenitors and cortical neuron progenitors (d). Pluripotency genes OCT4, SOX2, and NANOG were analyzed in all samples. $n=2$ independent experiments. e, $\mathbf{f}$ The absolute $(\mathbf{e})$ and relative $(\mathbf{f})$ expression of nuclear IncRNAs in undifferentiated human ESCs and germ layer and tissue progenitors as in b-d based on RT-qPCR analysis. $n=2$ (CNP), 3 (LM, MSC), 4 (LP, pluripotent, NSC), 5 (DE) independent experiments, error bars represent standard deviation, $p$ values were calculated by unpaired $t$-test; ${ }^{*} p<0.05,{ }^{* *} p<0.01,{ }^{* * *} p<0.001,{ }^{* * * *} p<0.0001$. Cells at different passages were used for replicates. Abbreviations: LM: lateral mesoderm, MSC: mesenchymal stem cells, DE: definitive endoderm, LP: lung progenitors, CNP: cortical neuron progenitors, NSC: neural stem cells

We screened 27 lncRNAs (Additional file 5: Table S3) that participate in the regulation of gene expression [22], including some that are known to form condensates [23], and found that the vast majority of them, 24, were either up- or downregulated upon differentiation, but mostly not in an obvious differentiation stage-specific manner (Fig. 1e, f). A striking example of lineagespecific regulation was the induction of $H 19(p<0.0001)$ in lung progenitor cells. Importantly, several lncRNAs were upregulated in all germ layers and stages including PINCR, LINC00472, and NEAT1_2 $(p<0.05$ in $\geq 5$ lineages), in contrast to lncRNAs such as MALAT1 which were mostly constitutively expressed. We chose NEAT1_ 2 for an in-depth analysis of condensation behavior because it is well known to form paraspeckles that have been linked to the regulation of development and differentiation $[18,21]$.

\section{Atlas of paraspeckle trajectories during cell fate transitions}

As a basis for identifying cellular features that are associated with the formation of paraspeckles, we differentiated hPSCs to more than 20 cell types and quantified foci of NEAT1_2, the facultative marker of paraspeckles [19], using single-molecule FISH (smFISH). Mesoderm was represented by differentiating MSCs to adipocytes and osteocytes, lateral mesoderm to cardiomyocytes, and intermediate mesoderm to nephron progenitors and matured nephrons; definitive endoderm cells were differentiated to hepatocytes and lung progenitors; NSCs, which belong to ectoderm, were differentiated to motor neurons and astrocytes, and cortical neuron progenitors were cultured to a mature state; neural crest progenitors, which give rise to multiple lineages that migrate throughout the body [24], were produced from neurospheres [25]. Extraembryonic tissues were represented by trophoblast progenitors differentiated from hPSCs [26], and myotubes, keratinocytes, and fibroblasts were derived from primary tissues (Fig. 1a).

We based cell type classifications on the analysis of characteristic proteins, transcripts, and additional features as follows: differentiated MSCs exhibited lipid droplets and calcium deposits, which are associated with adipocytes and osteocytes, respectively (Additional file 1: Figure S1g, h); differentiation of lateral mesoderm progenitors led to upregulation of cardiomyocyte progenitor markers including NKX2.5 and ISL1 (and spontaneous beating was observed) and downregulation of early mesoderm markers $T$ and MESP1 (Additional file 1: Figure S1i); markers of the developing kidney, SIX2, PAX2 CDH5, WT1, and additional nephron progenitor markers were expressed (Fig. 2a and Additional file 1: Figure $\mathrm{S} 1 \mathrm{j}, \mathrm{k}$ ). Endoderm differentiation was apparent by expression of liver markers AFP, ALB, and HNF4A (Fig. 2a and Additional file 1: Figure S1l). Characterization of the neuronal cell populations was based on the formation of TUBB3 and NFH-positive axons in the case of motor neurons, MAP2-positive axons in the case of cortical neurons, and GFAP-positive star-like projections in the case of astrocytes (Fig. 2a). Moreover, these cell populations expressed the characteristic transcription factors $M N X 1, I S L 1, T B R 1$, and SOX9, respectively (Fig. 2a), which were confirmed by analysis of the mRNAs together with neuronal markers CHAT and TBR2 as well as markers of astrocytes SLC1A2 and SLC1A3 (Additional file 1: Figure S1m-o). Finally, the identity of fibroblasts and keratinocytes was validated by expression of VIM / HSP47 and KRT14 / $I V L$, respectively (Fig. 2a).

Inspection of the cell atlas confirmed the previous observations that the number of paraspeckles increases when hPSCs exit the pluripotent state [18, 27]. Moreover, it was apparent that the increase in the number of paraspeckles during exit from pluripotency is a general phenomenon that encompassed progenitors of the three germ layers, neural crest progenitors, and extraembryonic trophoblast progenitors (Fig. $2 \mathrm{~b}$ and Additional file 2: Figure S2a, c). Because these types of progenitors exhibited vastly different transcriptional programs and epigenetic landscapes [28, 29], these results indicated that the regulation of paraspeckle formation is connected to a general mechanism of nuclear organization. Formation of heterochromatin upon differentiation is one such mechanism [30], however, the fact that the number of 


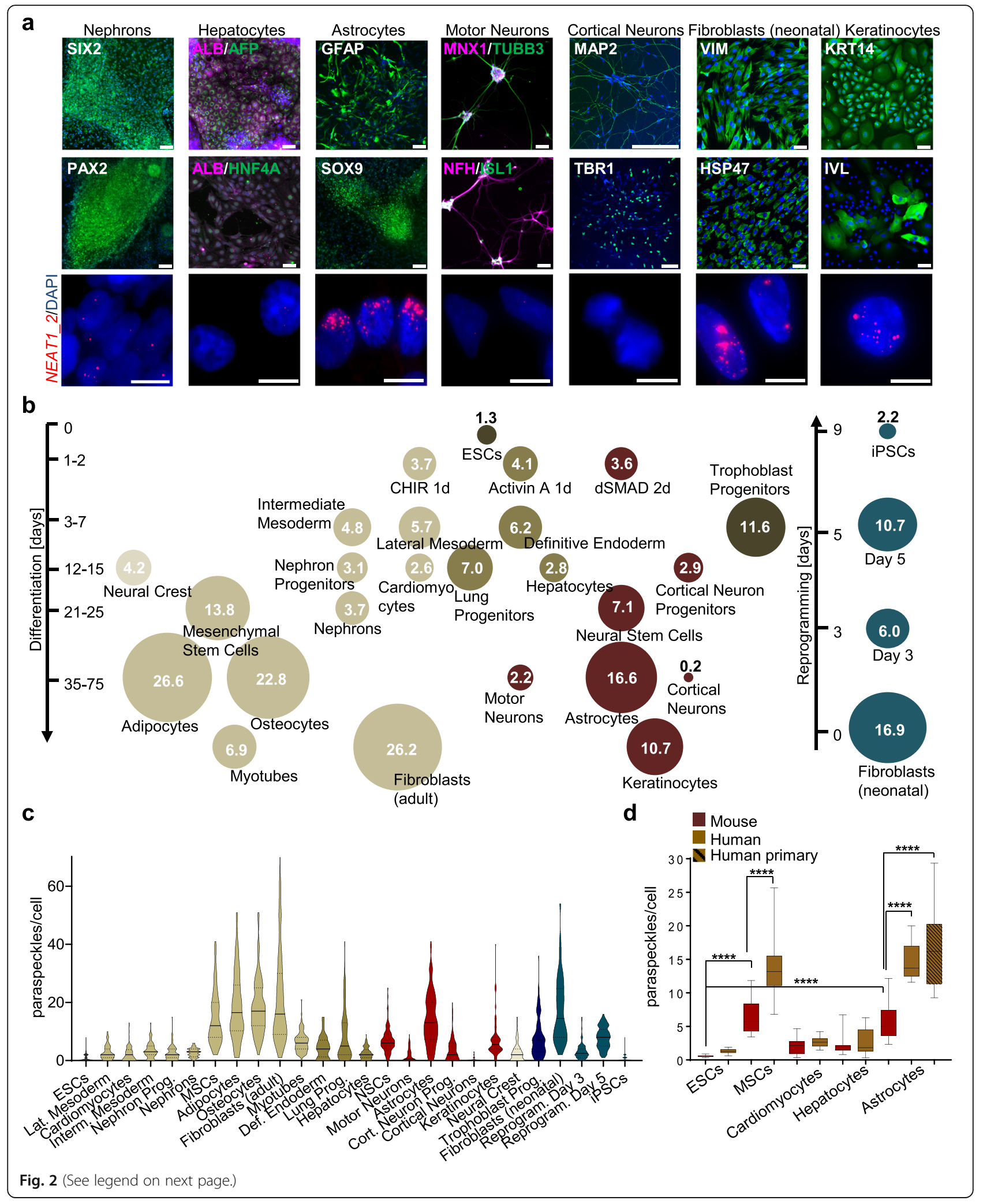


(See figure on previous page.)

Fig. 2 Characterization of paraspeckles in a panel of cell types and differentiated states. a Representative immunocytochemistry images of terminally differentiated cell preparations stained with antibodies, specific for markers of the respective cell types (scale bar upper panels: $50 \mu \mathrm{m}$ ) and analyzed by smFISH with NEAT1_2 probe (bottom panel, probe in red, DAPI staining in blue; scale bar: $10 \mu \mathrm{m}$ ). b A summary of the number of paraspeckles in diverse developmental and terminally differentiated cell types, and during reprogramming of human neonatal fibroblasts (Additional file 2: Figure S2ik). Size of circles corresponds to the average number of paraspeckles in the different cell types quantified by automated spot (foci) detection in a total of 200-2000 cells per type representing three independent experiments (single data points and statistics in Additional file 2: Figure S2c) c Violin plots depicting the number of paraspeckles in 100 single cells from all tested human cell types based on $\mathbf{b}$, black line represents mean value and dashed lines represent the quartiles. $\mathbf{d}$ Quantification of paraspeckle in primary murine cell types ( $n=3$ independent replicates using ESCs, or three tissue preparations for the other cell types with 10-28 images in total per condition). Representative images in Additional file 2: Figure S2f shown next to the corresponding human cell populations from $\mathbf{b}$. Error bars represent standard deviation, ${ }^{* * *} p<0.0001$ unpaired $t$-test

paraspeckles varied considerably between related types of cells spoke against it. For instance, differentiated cell types that belong to the mesoderm lineage displayed either 2.6-5.7 paraspeckles per cell on average, or 13.8-26 in MSCs and their adipocyte and osteocyte progeny (Fig. 2b and Additional file 2: Figure S2a-c). Similarly, in the neural lineages, there was a striking difference between the number of paraspeckles in the neurons and astrocytes that were derived from NSCs (Fig. 2b, c and Additional file 2: Figure S2c). Moreover, hepatocytes and lung progenitors exhibited differences in the number of paraspeckles despite their close endoderm origin. Additional evidence indicating that the regulation of the number of paraspeckles is not overtly determined by cell lineages or timing of differentiation were (a) the weak correlation between the number of paraspeckles and the time point of differentiation (Additional file 2: Figure S2e), (b) the oscillations in the number of paraspeckles during cellular reprogramming (the reverse process of differentiation) (Fig. 2b and Additional file 2: Figure S2i-k), and (c) that adult dermal fibroblasts exhibited significantly more paraspeckles compared to neonatal foreskin fibroblasts (Fig. 2b and Additional file 2: Figure S2c). Evidence indicating that the number of paraspeckles represents cellintrinsic regulation included passaging of neural stem cells which did not change the number of paraspeckles (Additional file 2: Figure S2d) and that primary tissue-derived human astrocytes exhibited similar amount of paraspeckles as the in vitro differentiated astrocytes (Fig. 2d).

To further analyze cellular traits that influence paraspeckle formation, we asked whether similar amounts of paraspeckles appear in equivalent types of cells from the mouse. Strikingly, we found that despite the trends being similar, i.e., astrocytes exhibiting greater amounts of paraspeckles compared to cardiomyocytes, hepatocytes, and ESCs, the number of paraspeckles in the respective types of cells in the mouse was significantly lower (Fig. $2 \mathrm{~d}$ and Additional file 2: Figure S2f). We substantiated these results by showing that the general correlation between the signal intensity of smFISH and the number of paraspeckles counted in human and mouse cells was very high and that the level of NEAT1_2 transcript was generally correlated (Additional file 2: Figure S2g, h). Altogether, we concluded that cellular differentiation creates diverse patterns of paraspeckle kinetics which are not overtly correlated with developmental lineages or timing.

\section{Paraspeckle amount correlates with the size of the nucleus}

One characteristic of the nucleus that varies drastically between different cell types is its size [31]. We therefore used our cell atlas image database to ask whether size scaling of the nucleus can explain the different amounts of paraspeckles in different cell types. Strikingly, we noticed a positive correlation between the number of paraspeckles and the size of nuclei when inspecting individual fibroblasts (Fig. 3a, b). Moreover, we noted a greater amount of paraspeckles in fibroblasts that were derived from adult compared with neonatal foreskin fibroblasts (Fig. 3b and Additional file 2: Figure S2c), which could be the result of an increase in cellular senescence accompanied by nucleus size increase [32]. These results prompted us to investigate whether the size of the nucleus is in general predictive for paraspeckle quantity in different types of cells (Fig. 2). Strikingly, analyzing the nucleus size in all the cell types of the atlas revealed a correlation with the number of paraspeckles (Fig. 3c). Furthermore, we found that the oscillating pattern of paraspeckle formation during reprogramming could be explained by changes in the average size of the nucleus during the process (Fig. 3d). This led us to hypothesize that the differences in paraspeckle amount between human and mouse astrocytes and MSCs (Fig. 2d) are due to nucleus size differences. Indeed, adjusting the number of paraspeckles to nucleus size differences between human and mouse MSCs and astrocytes showed that the normalized values of paraspeckles are similar between the species (Fig. 3e, f). Finally, the differences in paraspeckle numbers between human neonatal and adult fibroblasts could be explained in the same way by nucleus size changes (Fig. 3g, h). These results provided a first explanation for the high degree of variability in the number of paraspeckles observed between cells of the same type, between different types of cells and between species.

Finally, to assess whether the size of the nucleus determines the amount of paraspeckles or vice versa, we analyzed 


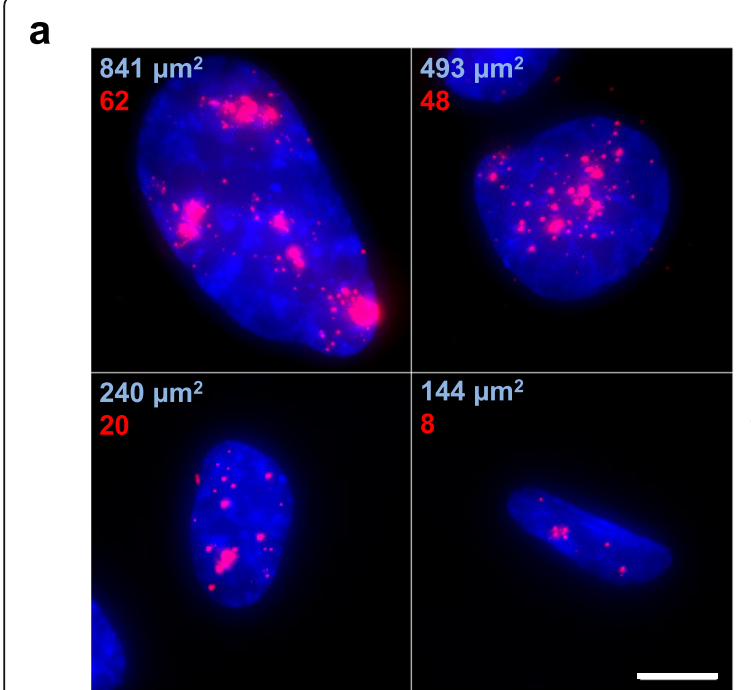

b

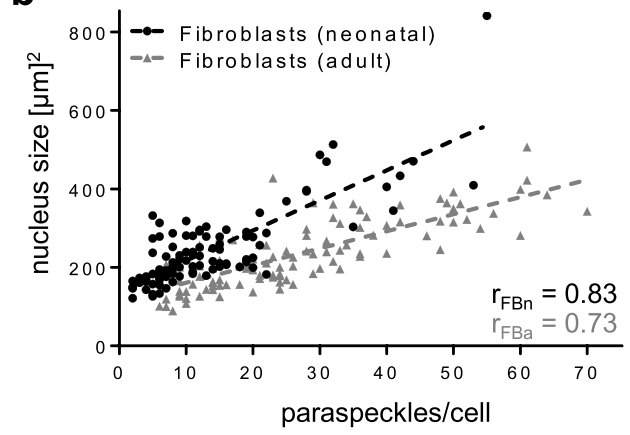

C

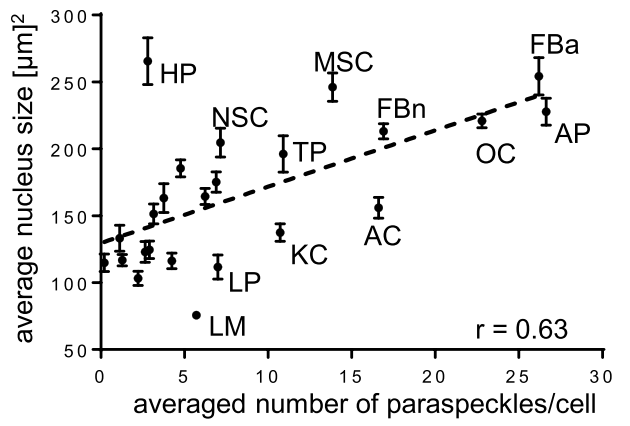

d

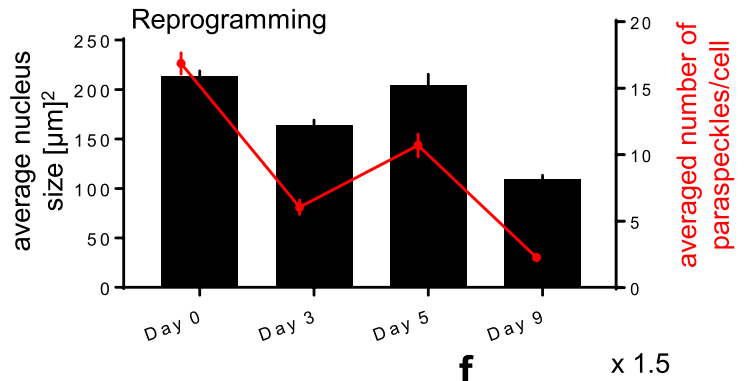

e

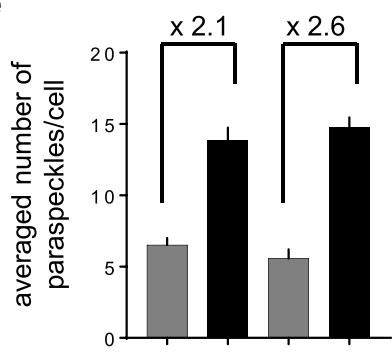

g ${ }_{M M S}{ }_{n M S C}{ }_{m A C}{ }_{n A C}$
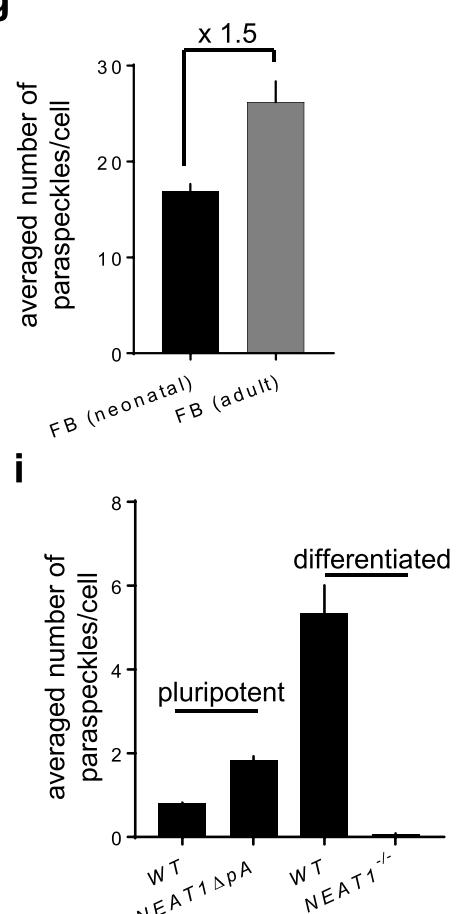

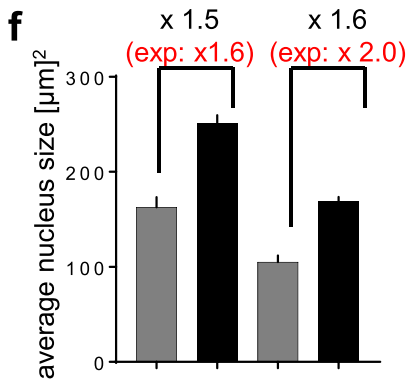

h ${ }_{m M S}{ }_{n}{ }_{n} S^{C}{ }_{m A}{ }^{C}{ }_{n A C}$

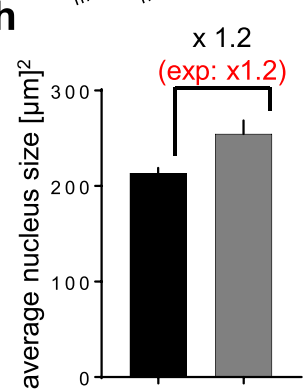

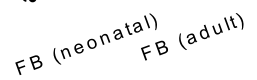

j

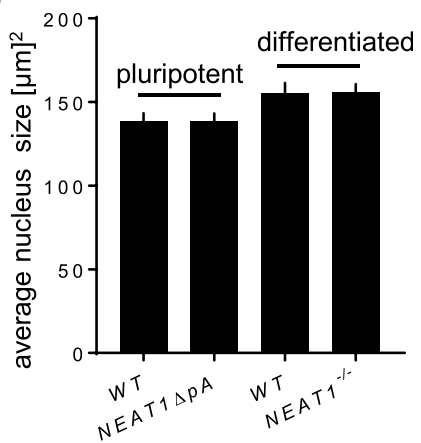

Fig. 3 Paraspeckle formation correlates with the size of nucleus. a Images and quantification of nuclear area $\left(\mu m^{2}\right)$ by DAPI staining (blue) and number of NEAT1_2 foci analyzed by smFISH (red) of representative human adult neonatal fibroblasts that exhibited different sizes (scale bar: $10 \mu \mathrm{m}$ ). $\mathbf{b}$ Analysis of the correlation between the number of paraspeckles and nucleus size of 100 human neonatal (black) and adult (gray) fibroblasts. c Analysis of the correlation between the averaged number of paraspeckles and average nucleus size per cell in 24 cell types analyzed in the atlas database represented in Fig. 2b. $\mathbf{d}$ Average nucleus size (black) and number of paraspeckles (red; based on Fig. 2b) analyzed during reprogramming of human neonatal fibroblasts. e-h Averaged number of paraspeckles per cell $(\mathbf{e}, \mathbf{g})$ based on Fig. 2b, $d$ and average nuclear size (f, $\mathbf{h})$ in mouse (gray) and human (black) MSCs and astrocytes (AC), as well as in adult (gray) and neonatal (black) fibroblasts. Numbers on top are the fold changes between the respective cell types from human and mouse. The numbers in red represent predicted fold changes based on slope of regression line in $\mathbf{c}$. i, $\mathbf{j}$ Average number of paraspeckles per cell (i) and average nucleus size $\mathbf{j}$ ) of $N E A T 1^{-1-}$, NEAT1 $\triangle P A$ and WT hESCs in pluripotent condition or differentiated by addition of retinoic acid for 3 days to induce paraspeckle formation [18]. The generation of $N E A T 1^{-1-}$ hESCs is outlined in Fig. 5a-d. Nucleus size represents the averaged value of 7-14 images per cell type from two independent experiments with 10-100 cells per image (details in methods). Error bars represent standard error of the mean. $r$ in $\mathbf{b}, \mathbf{c}$ represents Pearson's correlation coefficient and dashed line is the linear regression line 
$N E A T 1^{-1-}$ (introduced in detail in Fig. 5a) and NEAT1 $\triangle p A$ hESCs which either lacked paraspeckles or exhibited a twofold increase in the amount of paraspeckles due to the deletion of the internal polyA site [18] (Fig. 3i). Analyzing the size of nuclei did not reveal differences between NEAT1modified cell lines compared to wildtype (Fig. 3j), thus we concluded that it is the nucleus size that likely determines the amount of paraspeckles.

\section{DNA accessibility is required for paraspeckle assembly}

The broad range of the number of paraspeckles in cells with different nucleus size led us to interrogate what common traits could regulate their structural similarity across different types of cells. Because several lncRNAs, including NEAT1_2 and MALAT1, have been associated with formation of RNA-dsDNA triple helix structures through base pairing in the major groove $[13,33]$, we hypothesized that conformational changes of the DNA helix could perturb paraspeckles. We therefore tested whether small molecules such as ActD that binds the minor groove in dsDNA can promote the disassembly of paraspeckles. Strikingly, we noted the appearance of numerous small NEAT1_2 speckles that peaked between 1 and $2 \mathrm{~h}$ in diverse types of cells after treatment by ActD, including trophoblast progenitors, neural stem cells, and definitive endoderm progenitors that were derived from hPSCs, as well as in primary astrocytes and adult dermal fibroblasts (Fig. 4a and Additional file 3: Figure S3a). Importantly, the numbers of small NEAT1_2 speckles matched the number of paraspeckles observed in the respective cell types (Figs. $2 \mathrm{~b}$ and 4c), indicating that ActD induced the disintegration of paraspeckles. Contrarily, we noted that core paraspeckle proteins, namely SFPQ and NONO localized to perinucleolar caps after addition of ActD (Additional file 3: Figure S3b) which is in line with previous observations that reported perinucleolar localization of paraspeckle proteins after transcriptional inhibition [34] and during cell division [35] when NEAT1_2 is downregulated. Collectively, these results indicated that the disintegrated speckles of NEAT1_2 that were produced by ActD treatment were not functional.

Based on these findings, we further tested the effects of Hoechst 33342 and mithramycin A which induce conformational changes of the dsDNA helix by binding to the minor groove [36, 37]. These compounds led to the appearance of small NEAT1_2 speckles that exhibited similar patterns of accumulation and decay as by ActD (Fig. 4b, d). Importantly, $\alpha$-amanitin (selective inhibitor of RNA polymerases II, III, and IV) did not induce immediate paraspeckle disintegration (Fig. 4b, d), which ruled out the possibility that inhibition of RNA polymerases was the underlying cause. Nevertheless, the disappearance of NEAT1_2 following several hours of continuous treatment was likely due to other mechanisms that interfere with transcription as it has been shown that inhibition of transcription impairs paraspeckle formation $[38,39]$. It is known that some small DNA-binding molecules can induce double-strand breaks [40], which can be analyzed by the appearance of $\gamma-\mathrm{H} 2 \mathrm{AX}$ foci [41]. We found this to be the case following ActD treatment but not following Hoechst or mithramycin A (Fig. 4e and Additional file 3: Figure S3c). We concluded that immediate paraspeckle disintegration is not mediated by DNA damage or inhibition of RNA polymerases.

Because ActD and mithramycin A are used in chemotherapy protocols to treat several types of cancer [42], we were interested whether paraspeckle disintegration could be induced by other chemotherapeutic reagents. We tested this by treating the cells with the microtubule inhibitor vincristine [43], the topoisomerase II inhibitor etoposide [44], and flavopiridol, an inhibitor of cyclindependent kinases [45]. We observed a significant increase in small NEAT1_2 speckles after treatment by etoposide and flavopiridol, but not by vincristine (Fig. 4f), and since only the first two were shown to bind dsDNA $[46,47]$, this supported our conclusion that DNA binding by small molecules induced paraspeckle disintegration (Additional file 3: Figure S3d).

Finally, to test whether small DNA-binding molecules can in general disintegrate lncRNA condensates, we analyzed MALAT1 speckles by smFISH after ActD treatment. Strikingly, we found that MALAT1 speckles disintegrated with similar kinetics as paraspeckles (Additional file 3: Figure S3e, f). We concluded that dsDNA helix binding serves as structural basis for assembly and maintenance of paraspeckles and other nuclear lncRNA condensates.

\section{NEAT1_2 regulates differentiation}

Our results revealed that paraspeckles are dynamically regulated in cellular differentiation by the size of the nucleus and DNA accessibility. In order to analyze their functional role during the differentiation of germ layer progenitors, which commonly upregulate paraspeckles upon exit from pluripotency (Fig. 2), we created a series of genetically edited lines. This included deletion of the promoter, the transcription start site, and downstream sequences of NEAT1 in one line, deletion of the triple helix $(\mathrm{TH})$ sequence that resides in the 3 ' end of the gene, and insertion of poly (A) stop signal downstream to the transription start site. Because the $\mathrm{TH}$ is required for processing of NEAT1_2 [39], we hypothesized that its deletion will create a knock-down phenotype. Accordingly, we did not observe any paraspeckles and expression of NEAT1_2 in the $N E A T 1^{-/-}$line, and $57 \%$ less paraspeckles in the NEAT1 $\triangle T H$ line after spontaneous differentiation (Fig. 5a-d).

By analyzing the expression of developmental markers, we found that $N E A T 1^{-/-}$and NEAT1 $\triangle T H$ clones exhibited 


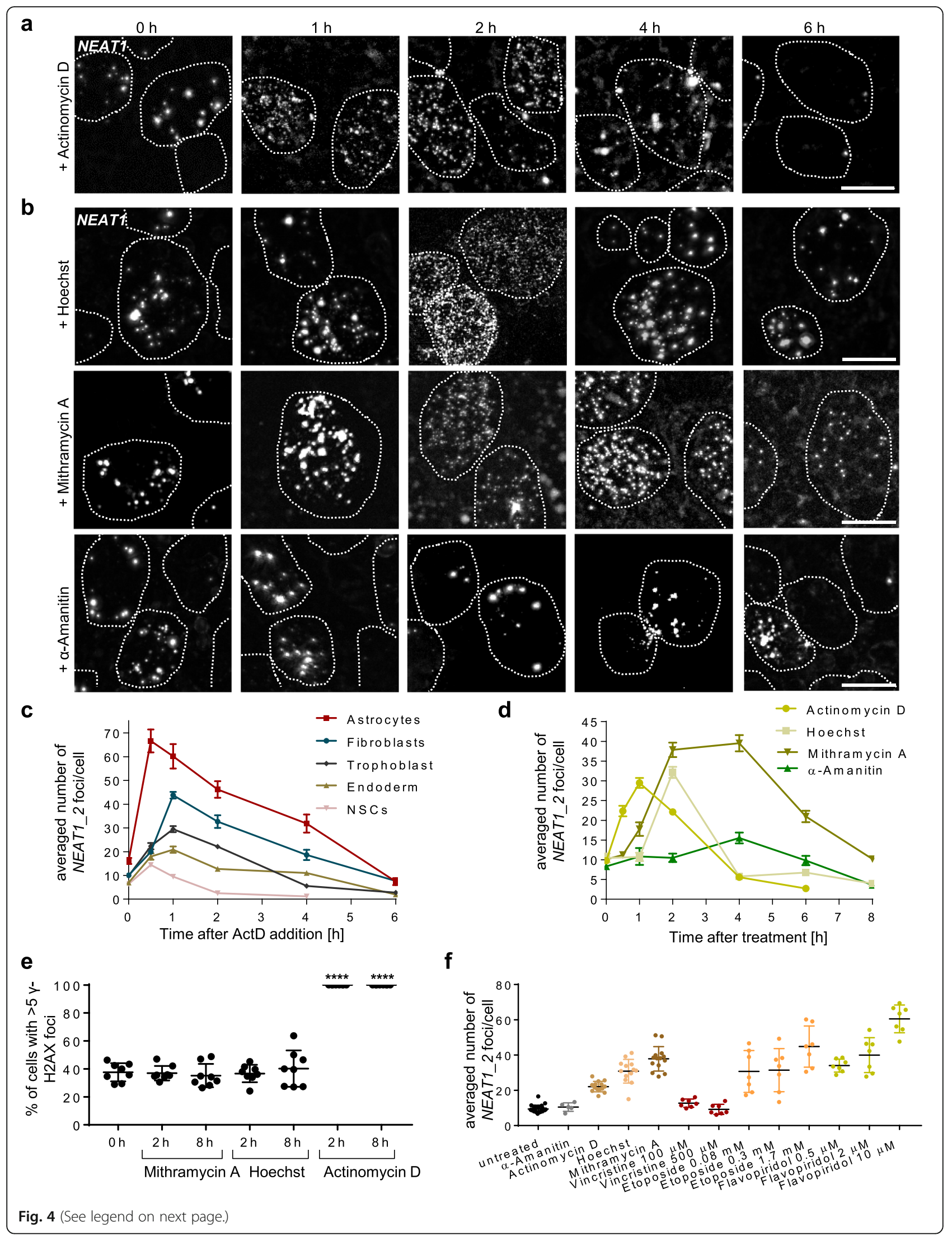


(See figure on previous page.)

Fig. 4 Treatment with DNA-binding small molecule compounds promotes paraspeckle disassembly. a, b Representative images of NEAT1_2 smFISH after treatment of cells by $2 \mu \mathrm{M}$ ActD (a), $100 \mu \mathrm{g} / \mathrm{ml}$ Hoechst 33342, $5 \mu \mathrm{M}$ mithramycin A, and $50 \mu \mathrm{M}$ a-amanitin (b) in trophoblast progenitors produced by 3-day BMP4 treatment of hESCs. Dashed lines show the locations of the borders of the nuclei. Scale bar: $10 \mu \mathrm{m}$. c Analysis of the averaged amount of NEAT1_2 foci following ActD treatment in five different cell types. Images in Additional file 3: Figure S3a. d Analysis of the averaged amount of NEAT1_2 foci in trophoblast progenitors following treatment by the four compounds shown in $\mathbf{a}$, $\mathbf{b}$. e Quantification of $\mathrm{\gamma}$-H2AX foci (associated with DNA double-strand breaks) in trophoblast progenitors and after addition of DNA-binding compounds. Representative images in Additional file 3: Figure S3c. f Analysis of the averaged amount of NEAT1_2 foci in trophoblast progenitors following $2 \mathrm{~h}$ of treatment by the compounds as in $\mathbf{a}, \mathbf{b}$ and different concentrations of the chemotherapeutic reagents vincristine, etoposide, and flavopiridol. DNA-binding and transcriptional inhibition properties of the compounds are listed in Additional file 3: Figure S3d. Error bars in c, d represent standard error of the mean and standard deviation in $\mathbf{e}$, $\mathbf{f}$. Seven images were analyzed in $\mathbf{e}, \mathbf{f}$ and 14 in c, d, representing two independent replicates using cells of different passages. ${ }^{* * * *} p<0.0001$ unpaired $t$-test

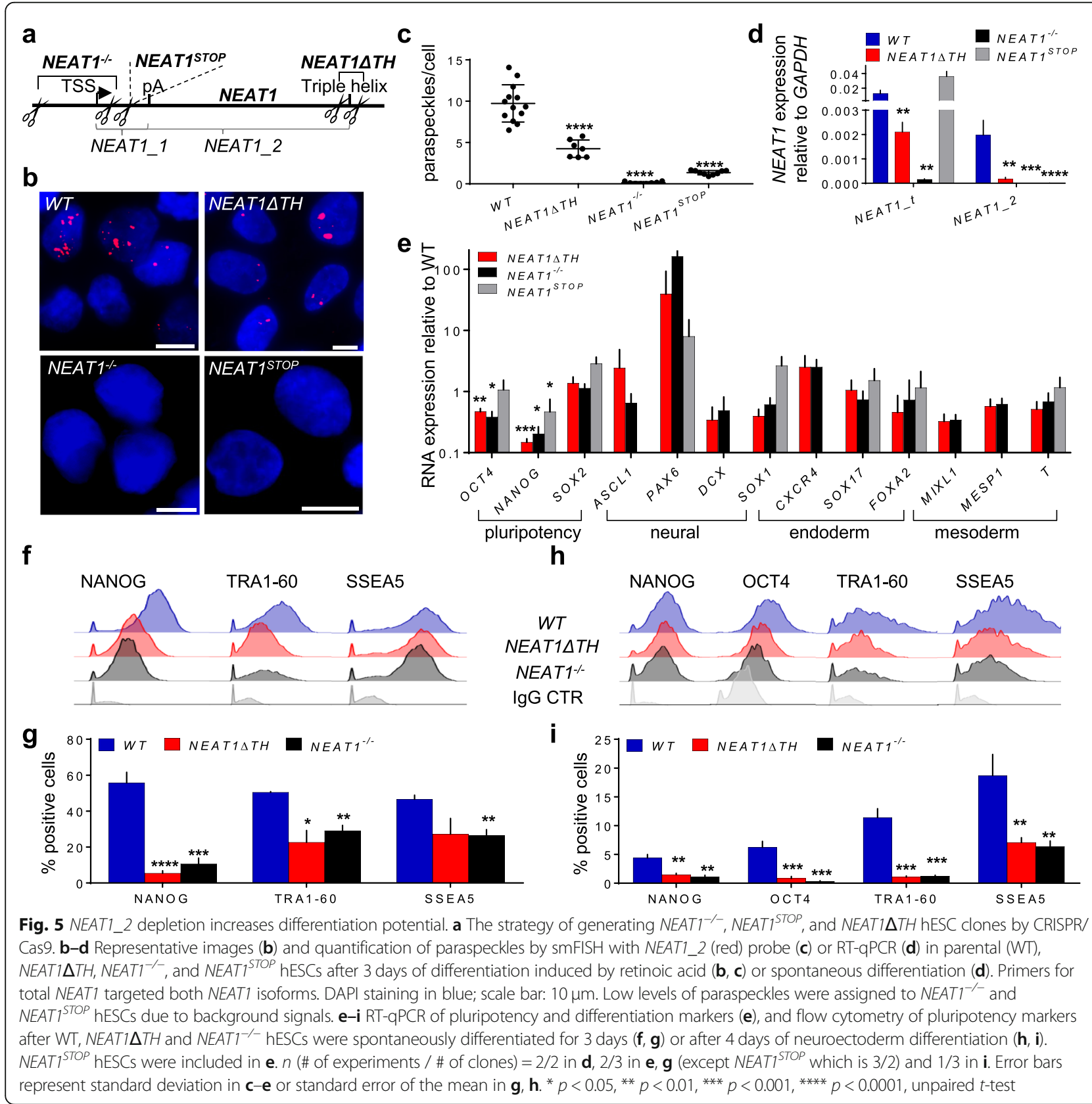


normal characteristics of undifferentiated cells with the exception of premature upregulation of FOXA2 and PAX6 (Additional file 4: Figure S4a). Remarkably, the induction of spontaneous differentiation revealed acceleration of the downregulation of pluripotency transcription factors OCT4 and NANOG and cell surface markers TRA1-60 and SSEA5 in $N E A T 1^{-/-}$and NEAT1 $\triangle T H$ cells compared to the parental cells one day following the appearance of paraspeckles (Fig. 5e-g and Additional file 4: Figure S4b, c). A similar acceleration was observed during neuroectoderm differentiation, albeit the gene expression patterns became similar to the parental line at later stages of differentiation (Fig. 5h, i and Additional file 4: Figure S4d). As we observed similar phenotypes for $N E A T 1^{-/-}$and $N E A T 1 \triangle T H$ cell lines (Fig. 5e-i and Additional file 4: Figure S4a-d), despite the latter being able to produce the short isoform (Fig. 5d), we hypothesized that NEAT1_1 is dispensable for differentiation of germ layer progenitors. Indeed, analyzing the differentiation of a line that harbored a deletion of the internal polyadenylation site in NEAT1 (NEAT1 $\triangle p A)$, and hence was not capable of expressing NEAT1_1 [18], did not reveal a difference in the up- and downregulation of differentiation and pluripotency genes (Additional file 4: Figure S4eg). Furthermore, $N E A T 1^{\text {STOP }}$ cells exhibited accelerated downregulation of the pluripotency transcription factors OCT4/NANOG and the surface markers SSEA4/SSEA5/ TRA1-60 during spontaneous differentiation (Additional file 4: Figure S4h-k), similar to the $N E A T 1^{-/-}$and NEAT1 $\triangle T H$ lines.

We concluded that only condensated NEAT1, namely paraspeckles, are functionally important during spontaneous or neural differentiation of hPSCs by slowing down the process, but cells can compensate for the loss of paraspeckles by further differentiation.

\section{Discussion}

LncRNAs are predominantly localized in the nucleus [48] where some have been implicated in the architectural organization of chromatin by formation of condensates [22]. In this regard, NEAT1 is paradigmatic for studying lncRNA condensation because it is the vital scaffold for the formation of paraspeckles together with RBPs and chromatin factors that have been wellcharacterized $[6,9,49]$. Despite major advancements in understanding the molecular structure of paraspeckles and the regulation of NEAT1 RNA [39, 50], basic questions pertaining to the regulation of paraspeckle formation, quantities in cells, and their molecular and cellular functions remain open. Here, we made several observations that shine light on these questions.

First, we show that the amount of paraspeckles in cells within a population, or among different cell populations, is generally proportionally scaled to the size of the nucleus. This finding could have important implications, for example, it could indicate that paraspeckles are engaged in feedback(s) that slow-down cellular processes when nuclei reach set size(s), such as energy production. In this regard, paraspeckles have been implicated recently in the regulation of mitochondria homeostasis [51], and their upregulation following viral infection [9] and in tumor cells [52] could be further indications of this connection [53]. Interestingly, we noted that certain cell types deviate substantially from the nucleus size rule, most notably hepatocytes, which could indicate complex forms of regulation by paraspeckles in specific types of cells. The nucleus sizing effect could also indicate that the regulation of paraspeckles is more pronounced in human stem cell differentiation, and plausibly also in human development, compared to the equivalent processes in the mouse since nuclei in mouse cells are often significantly smaller and contain fewer paraspeckles compared to corresponding human cell types. In line with this idea is the fact that paraspeckles are not vital for mouse development past the blastocyst stage [20,21], although their knock-down in embryos at the gastrulation stage increases the odds of developmental perturbations [18]. Collectively, the new connection that we found between the scaling of the nucleus to paraspeckle-mediated regulation emphasizes that dissecting the molecular and cellular functions of paraspeckles should take into account processes that could be affected by nucleus size scaling. It is important to note that our data revealed only a correlative link between the size of the nucleus and the amount of paraspeckles, and further experiments should elaborate the manipulation of nucleus size in relation to the effect on paraspeckle formation in order to establish a causal relationship.

Second, by applying small molecules that can associate with the minor groove of dsDNA, we found strong evidence that paraspeckles and other nuclear speckles are tethered to the DNA, most likely by forming triple helix structures $[13,33]$. The fact that molecules with vastly different structures can promote paraspeckle disintegration indicates that conformational changes of DNA are the common cause. These findings imply that numerous lncRNAs are anchored in the genome to regulate its biochemical functions. If this is proven by future studies, it would indicate that aberrant regulation of tethered lncRNA condensates could be involved in human disease. In line with this prediction, a growing list of lncRNAs has been associated with different disorders, including diabetes [54] and cancer [55]. Therefore, our finding of small molecules that disintegrate tethered lncRNA condensates could lead to development of potential novel therapeutic approaches that are based on lncRNA disintegration. The fact that several of the molecules that we implicated here in the disintegration of 
paraspeckles and other nuclear speckles are approved chemotherapies, suggests that their clinical assessments could be expedited. On the other hand, as we implicated common chemotherapies in disintegration of lncRNA foci, it is important to consider the possibility that on-target and/or side effects in cancer therapy are mediated by changes of the structures of lncRNAs. Therefore, our results could be important for creating a new path to understand the mode-of-action in the treatment of certain cancers, for example, by actinomycin D, etoposide, and mithramycin A, which are commonly used in the treatment of osteosarcoma $[42,56]$. Taken together with our assessment of the functional importance of paraspeckles in stem cell regulation, we suggest that their involvement in slowing down differentiation processes is connected to dsDNA tethering.

\section{Conclusion}

We provide a comprehensive quantification of paraspeckles in an atlas of human cell types. Based on this, we deduce common cellular features that indicate how paraspeckle formation is regulated, namely by cells' nucleus size which positively correlates with the number of paraspeckles and DNA tethering. Perturbing the latter by small dsDNA-binding molecules disintegrates paraspeckles and other chromatin-embedded lncRNAs. Lastly, we show that paraspeckles are important for early stem cell differentiation, and thus their function in this intricate regulation may be connected to the increase of the nucleus size, which takes place during the differentiation of PSCs, as well as to architectural changes of chromatin that could affect their tethering.

\section{Methods}

\section{PSC culture}

Human ESCs of the H9 line (WiCELL Research Institute) and iPSCs were cultured in StemMACS iPS-Brew XF (Miltenyi Biotec) and passaged by StemMACS Passaging Solution (Miltenyi Biotec) on tissue culture-treated plates (Sigma) coated with Matrigel (Thermo Fisher Scientific) diluted 1:100 in DMEM/F-12 (Thermo Fisher Scientific). All differentiation experiments were carried out with $\mathrm{H} 9$ cells, except lung progenitor and cortical neuron differentiation, which were performed with iPSC lines, namely NKX2.1-P2A-eGFP [57] and foreskin fibroblast-derived iPSCs [58], respectively. For paraspeckle measurements in trophoblast progenitors and neural crest cells, we used differentiation protocols, as previously described $[26,59]$.

\section{Fibroblast reprogramming}

The reprogramming of human neonatal dermal fibroblasts was performed using StemRNA 3rd Gen Reprogramming Kit (Reprocell) according to the manufacturer's protocol. The RNA transfection cocktail included synthetic, non- modified RNA of reprogramming factors OCT4, SOX2, KLF4, cMYC, NANOG, and LIN28A, immune evasion mRNAs of E3, K3, B18, and reprogramming-enhancing, mature, double-stranded microRNAs from the 302/367 cluster. $1.0 \times 10^{4}$ fibroblasts were plated per $60 \mathrm{~mm}$ organ culture dish (Corning), and reprogramming was started the following day by lipofection of the mRNA cocktail and incubation overnight. Transfections were repeated daily for 3 days and at day 9, distinct iPSC colonies were forming.

\section{Spontaneous differentiation}

One day prior to the beginning of spontaneous differentiation, $5.0 \times 10^{5}$ cells that were dissociated using Accutase (Sigma) were transferred to one Matrigel-coated well of a 12-well plate with StemMACS iPS-Brew XF and $10 \mu \mathrm{M}$ Y-27632 (R\&D Systems). After $24 \mathrm{~h}$, the medium was replaced with medium containing 20\% KnockOut Serum Replacement (KSR), 1\% GlutaMAX, $1 \%$ non-essential amino acids (NEAA), and $0.1 \mathrm{mM}$ beta-mercaptoethanol (all Thermo Fisher Scientific). Fresh medium was applied daily for up to 3 days.

\section{MSC, adipocyte, and osteocyte differentiation}

MSC differentiation was induced by exchanging StemMACS iPS-Brew XF medium with differentiation medium containing 20\% KSR, $1 \%$ GlutaMAX, 1\% NEAA, and $0.1 \mathrm{mM}$ beta-mercaptoethanol supplemented with $10 \mu \mathrm{M}$ SB431542 (Miltenyi Biotec). Fresh medium was applied every other day and after 7 days, cells were transferred in a 1:3 ratio to a non-coated tissue culturetreated plate with MSC expansion medium (Miltenyi Biotec). Fresh medium was applied daily before splitting the cells at differentiation day 14. Process control of MSC differentiation was performed by flow cytometry and RT-qPCR at day 21. At day 21, MSCs were differentiated to adipocytes or osteocytes using StemMACS AdipoDiff Media or StemMACS OsteoDiff Media (both Miltenyi Biotec), respectively. Fresh medium was applied every 3 days for 20 days before process control by OilRed $\mathrm{O}$ or Alizarin Red staining, respectively.

\section{Cardiomyocyte differentiation}

Cardiomyocytes were generated according to a published protocol [60]. Briefly, $1.0 \times 10^{6}$ cells were dissociated as single cells using Accutase and plated in a well of a 12well plate with StemMACS iPS-Brew XF and differentiation was induced the following day by changing the medium to RPMI-1640 (Sigma) with 2\% B-27 supplement without insulin (Thermo Fisher Scientific) and $10 \mu$ M CHIR99021(R\&D Systems). Same medium was used the following day, and at day 3 , half of the medium was replaced with RPMI/B-27 without insulin supplemented with $10 \mu \mathrm{M}$ IWP-2 (Santa Cruz Biotechnology). 
At days 5 and 7, RPMI/B-27 first without insulin and then with full B-27 (Thermo Fisher Scientific) was used. Fresh medium was applied after 3 days and cultures beginning to contract around day 12 were used for experiments. Process control of lateral mesoderm markers was performed at day 3 .

\section{Nephron differentiation}

The protocol for differentiation of nephrons was optimized based on a published protocol [61]. Starting with undifferentiated cell cultures of $\sim 70 \%$ confluency, a medium containing RPMI-1640, 1\% GlutaMAX and 2\% B-27 supplement (basal medium), $10 \mu \mathrm{M}$ CHIR99021, and $500 \mathrm{nM}$ dorsomorphin (Tocris) was used. Fresh medium was applied every other day and from day 4 onwards, the basal medium was supplemented with $10 \mathrm{ng} / \mathrm{ml}$ of Activin A (R\&D Systems). At day 7, basal medium was supplemented with $10 \mathrm{ng} / \mathrm{ml}$ FGF9 (R\&D Systems) and at day 9, with $3 \mu \mathrm{M}$ CHIR99021 in addition for $48 \mathrm{~h}$. Afterwards, basal medium supplemented with FGF9 was applied daily until day 21. Process controls were performed at day 7 for intermediate mesoderm markers, at day 14 for nephron progenitor markers, and at day 21 for nephron markers by RT-qPCR and immunostaining.

\section{Definitive endoderm, lung progenitor, and hepatocyte differentiation}

The protocol for differentiation of definitive endoderm was based on a published protocol [62]. Briefly, hPSCs were dissociated using Accutase and $4 \times 10^{5}$ single cells were seeded in a Matrigel-coated 24-well in RPMI-1640 medium, supplemented with $2 \%$ B-27, $50 \mathrm{U} / \mathrm{ml}$ of penicillin/streptomycin (Pen/Strep; Thermo Fisher Scientific), $100 \mathrm{ng} / \mathrm{ml}$ Activin A, $1 \mu \mathrm{M}$ CHIR99021, and $10 \mu \mathrm{M}$ Y-27632. Fresh medium was applied daily until day 6 without Y-27632, but with $0.25 \mathrm{mM}$ sodium butyrate (Sigma) on the first day and $0.125 \mathrm{mM}$ afterwards. Process controls were performed at day 6 by flow cytometry and RT-qPCR.

Subsequent differentiation towards lung progenitor cells was adapted from a published protocol [63]. Briefly, foregut endoderm was induced using day 6 definitive endoderm cells by DMEM/F-12 medium, supplemented with $1 \%$ GlutaMAX, 2\% B-27, 1\% N-2 (Thermo Fisher Scientific), $50 \mathrm{U} / \mathrm{ml}$ Pen/Strep, $0.05 \mathrm{mg} / \mathrm{ml}$ of L-ascorbic acid (Sigma), $0.4 \mathrm{mM}$ of monothioglycerol (Sigma) (basal medium), $2 \mu \mathrm{M}$ dorsomorphin, and $10 \mu \mathrm{M}$ SB431542. Fresh medium was applied daily and on day 10, lung progenitor differentiation was induced by applying basal medium supplemented with $20 \mathrm{ng} / \mathrm{ml}$ recombinant human BMP4 (R\&D Systems), $50 \mathrm{nM}$ retinoic acid (Sigma), and $3 \mu \mathrm{M}$ CHIR99021. Fresh medium was applied daily until differentiation day 15 when expression of NKX2.1 was observed.
Hepatocyte differentiation was based on a published protocol [64]. Briefly, $1.5 \times 10^{5}$ definitive endoderm cells were dissociated with Accutase, transferred to a Matrigel-coated 24-well plate, and treated by DMEM/F12 with 10\% KSR, 1\% NEAA, 1\% GlutaMAX, and DMSO (Sigma) together with $10 \mu \mathrm{M} \mathrm{Y-27632} \mathrm{and} 100$ $\mathrm{ng} / \mathrm{ml}$ recombinant human hepatocyte growth factor (R\&D Systems). Medium was changed daily without Y27632 for 10 days, and process controls were conducted by RT-qPCR and immunofluorescence.

\section{Neural stem cell differentiation}

The protocol for differentiation of neural stem cells (NSCs) was based on the generation of neurospheres [65]. Briefly, hESCs were harvested using a $2 \mathrm{mg} / \mathrm{ml} \mathrm{col-}$ lagenase IV solution (Thermo Fisher Scientific) and resuspended in DMEM/F-12 medium supplemented with 20\% KSR, 1\% NEAA, 1\% GlutaMAX, $10 \mu$ M SB431542, $5 \mu \mathrm{M}$ dorsomorphin, $20 \mu \mathrm{M}$ CHIR99021, $10 \mu \mathrm{M}$ purmorphamine (Miltenyi Biotec), and $10 \mu \mathrm{M} \mathrm{Y}-27632$, and plated on an ultra-low attachment 6-well plate (Corning). Fresh medium was applied without Y-27632. 48 hours later, the basal medium was exchanged with N2B27-based medium containing a 1:1 mixture of DMEM-F-12 and Neurobasal A (Thermo Fisher Scientific) with $0.5 \% \mathrm{~N}-2,1 \% \mathrm{~B}-27$ minus vitamin A, $1 \%$ NEAA, and $1 \%$ GlutaMAX, and the small molecules described above. At day 5, N2B27-based medium supplemented with $50 \mu \mathrm{g} / \mathrm{ml} \mathrm{L-ascorbic} \mathrm{acid,} \mathrm{SB431542,} \mathrm{and}$ dorsomorphin was applied. At day 7 , the neurospheres were mechanically dissociated and plated on Matrigelcoated plates. 24 hours before the replating, the medium was supplemented additionally with $5 \mathrm{ng} / \mathrm{ml}$ bFGF (Peprotech). Plated neurospheres were maintained for 7 days using the same medium and on day 14 , confluent neuroepithelial outgrowths were passaged in a 1:10 dilution using collagenase IV. The NSC cultures were passaged every 7 days and maintained in N2B27 medium with SB431542, dorsomorphin, and bFGF at same concentrations as above with medium change every other day. Process control of NSC differentiation was performed at day 21 which we define as passage 1 .

\section{Astrocyte differentiation}

The protocol of astrocyte differentiation was based on a published protocol [66]. Briefly, tissue culture-treated plates were coated for $2 \mathrm{~h}$ with $10 \mathrm{ng} / \mathrm{ml}$ laminin/poly-Lornithine (Sigma), and day 21 NSCs were dissociated using Accutase and plated at a ratio of $2.8 \times 10^{5}$ cells per well of a 12-well plate with N2B27 medium supplemented with $20 \mathrm{ng} / \mathrm{ml} \mathrm{bFGF,} 10 \mathrm{ng} / \mathrm{ml}$ BMP4, and $5 \mathrm{ng} /$ ml CNTF (R\&D Systems). On day 15, medium was supplemented with $10 \mathrm{ng} / \mathrm{ml}$ bFGF, $10 \mathrm{ng} / \mathrm{ml}$ EGF (Sigma), and $10 \mathrm{ng} / \mathrm{ml}$ neuregulin (R\&D Systems), and the cells 
were differentiated for additional 15 days and then analyzed.

\section{Motor neuron differentiation}

The motor neuron differentiation was based on a published protocol [67]. Briefly, plates were coated, first with $10 \mathrm{ng} / \mathrm{ml}$ laminin, poly-L-ornithine, collagen I, and collagen IV (Sigma) for $1 \mathrm{~h}$ each and then with $10 \mathrm{ng} / \mathrm{ml}$ vitronectin (Peprotech) for $1 \mathrm{~h}$. Instead of vitronectin, $10 \mathrm{ng} / \mathrm{ml}$ fibronectin (Sigma) was used for later passaging. $1.5 \times 10^{5}$ day $21 \mathrm{NSCs}$ were seeded per well of a 12-well plate with N2B27 medium supplemented with $100 \mathrm{ng} / \mathrm{ml} \mathrm{SHH}, 10 \mathrm{ng} / \mathrm{ml}$ BDNF, $10 \mathrm{ng} / \mathrm{ml}$ GDNF, 10 $\mathrm{ng} / \mathrm{ml}$ IGF (all from R\&D System), and $100 \mathrm{nM}$ retinoic acid. After 15 days, the medium was supplemented with $0.1 \mu \mathrm{M}$ y-secretase inhibitor XXI (Merck) and $0.1 \mu \mathrm{M}$ cAMP (Sigma Aldrich). Cells were analyzed at day 75.

\section{Cortical neuron differentiation}

The protocol of cortical neuron differentiation was based on a previously published protocol [68], with minor modifications. Briefly, iPSCs were plated in a 1:1 mixture of DMEM/F-12 and Neurobasal A, 1\% N-2, 2\% B-27, 1\% GlutaMAX, $1 \%$ NEAA, $1000 \mathrm{U} / \mathrm{mL}$ Pen/Strep, $5 \mu \mathrm{g} / \mathrm{ml}$ human insulin (Thermo Fisher Scientific), and $0.1 \mathrm{mM}$ $\beta$-mercaptoethanol with $10 \mu \mathrm{M}$ SB431542 and $1 \mu \mathrm{M}$ dorsomorphin, and fresh media was applied daily. At day 10, cells were dissociated with Accutase and plated on poly-L-ornithine- (1:1000) and laminin- (1:200) coated plates at 1:4 dilution with the same medium supplemented with $10 \mu \mathrm{M}$ Y-27632. From the next day onwards, the cells were treated by medium without SB431542 and dorsomorphin. Cells were passaged every 6 days. Process control for neural induction and cortical neuron progenitor differentiation was performed after 15 and 35 days.

\section{Somatic cell lines}

Somatic cell lines used in this study were $\mathrm{GIBCO}^{\circ}$ Human Skeletal myoblasts that were cultured for 2 days in DMEM (Thermo Fisher Scientific) together with 2\% horse serum (Thermo Fisher Scientific) which induced differentiation to myotubes. Additionally, primary human epidermal keratinocytes (ATCC PCS200011 $^{\mathrm{mm}}$ ), primary adult human dermal fibroblasts (ATCC ${ }^{\circ}$ PCS201012 $2^{\mathrm{mm}}$ ), primary human neonatal foreskin fibroblasts (ATCC CRL-2522 $^{\text {mom}}$ ), and primary human astrocytes (ScienCell ${ }^{\mathrm{Tw}}$ Research Laboratories, \#1800) were cultured according to the provider's instructions.

\section{Derivation of murine mesenchymal stem cells}

Cultures of murine mesenchymal stem cells were established from the femoral bone marrow of female FVB/N mice (Charles River Laboratories, Sulzbach, Germany) by aspiration from the marrow cavity with $1 \mathrm{ml}$ ice-cold PBS and a 0.4-mm injection needle. A solution of single cells was produced by pipetting, filtering through a 70$\mu \mathrm{m}$ cell strainer (BD), and $5 \mathrm{~min}$ centrifugation at $300 \mathrm{~g}$. Cells were plated in $12 \mathrm{ml}$ of DMEM/F-12 with $1 \mathrm{~g} / \mathrm{l}$ glucose, 10\% MSC-qualified FBS (Thermo Fisher Scientific), $1 \%$ GlutaMAX, and $10 \mu \mathrm{M}$ Y-27632 in T75 cell culture flasks. Cells were kept under hypoxic conditions $\left(2 \% \mathrm{O}_{2}\right.$, $\left.5 \% \mathrm{CO}_{2}\right)$ at $37^{\circ} \mathrm{C}$ in a humidified atmosphere. Nonadherent cells were depleted by exchanging the medium 2 and $4 \mathrm{~h}$ after initial plating, whereas later on, fresh medium was applied every 3.5 days. When reached approximately $80 \%$ confluency, cells were passaged in a $1: 3$ ratio using Accutase.

\section{Derivation of primary murine astrocytes}

Primary mouse astrocytes of the C56BL/6 P3 strain were derived from whole cortex preparations. The brain was washed with HBSS (Sigma) supplemented with $50 \mathrm{U} / \mathrm{ml}$ Pen/Strep, and meninges and blood vessels were removed. The cortex was isolated and cut into smaller pieces and further resuspended in $10 \mathrm{ml} \mathrm{HBSS} / \mathrm{Pen} /$ Strep. The minced tissue was plated on poly-D-lysinecoated plates $(40 \mu \mathrm{g} / \mathrm{ml}, 1 \mathrm{~h}$ incubation) in DMEM/F-12 supplemented with $10 \% \mathrm{FBS}, 50 \mathrm{U} / \mathrm{ml}$ Pen/Strep, $10 \mathrm{ng} /$ $\mathrm{ml}$ FGF2, and $10 \mathrm{ng} / \mathrm{ml}$ EGF. Fresh medium was applied every other day until the culture became confluent.

\section{Derivation of primary murine cardiomyocytes}

Primary mouse cardiomyocytes cultures were prepared using the Primary Cardiomyocyte Isolation Kit (Thermo Fisher Scientific) according to the manufacturer's instructions.

\section{Derivation of primary murine hepatocytes}

The protocol of primary hepatocyte derivation was based on a published protocol [69]. Liver was obtained from 14-week-old C56BL/6 mice and digested using $2 \mathrm{mg} / \mathrm{ml}$ collagenase IV solution (Thermo Fisher Scientific) at $37^{\circ} \mathrm{C}$ for $45 \mathrm{~min}$. The digested tissue was plated in a 10 $\mathrm{cm}$ dish with Williams E medium (Sigma) supplemented with 5\% FBS and mechanically dissociated. Then, cells were filtered using a $70-\mu \mathrm{m}$ cell strainer, and $6 \mathrm{ml}$ cell suspension was layered on top of a Percoll (Sigma) gradient of $1.12 \mathrm{~g} / \mathrm{ml}, 1.08 \mathrm{~g} / \mathrm{ml}$, and $1.06 \mathrm{~g} / \mathrm{ml}$ in PBS. Cells were centrifuged for $20 \mathrm{~min}$ at $800 \mathrm{~g}$ and washed with Williams E medium with 5\% FBS. After another centrifugation at $300 \mathrm{~g}$ for $10 \mathrm{~min}$, the cells were resuspended in Williams E medium with 5\% FBS, 1\% GlutaMAX, 50 $\mathrm{U} / \mathrm{ml}$ Pen/Strep, $50 \mathrm{ng} / \mathrm{ml}$ EGF, $1 \mu \mathrm{g} / \mathrm{ml}$ insulin, $10 \mu \mathrm{g} /$ $\mathrm{ml}$ transferrin (Sigma), and $1.3 \mu \mathrm{g} / \mathrm{ml}$ of hydrocortisone (Sigma) and plated on $10 \mu \mathrm{g} / \mathrm{ml}$ rat tail collagen I(Sigma) coated plates with daily medium change. 


\section{Oil Red 0 staining}

Following adipocyte differentiation, cells were washed twice with PBS, fixed with 10\% neutral buffered formalin (Sigma) for $45 \mathrm{~min}$, then washed twice with tap water and fixed again with 2-propanol (Sigma) for $5 \mathrm{~min}$. Filtered Oil Red $\mathrm{O}$ solution $(1.8 \mathrm{mg} / \mathrm{ml}$ in 2-propanol; Sigma) was added to the cells and incubated for $10 \mathrm{~min}$. After two washes with PBS, cells were counterstained with Mayer's hematoxylin solution (Sigma) for $3 \mathrm{~min}$, before two washes with tap water, addition of PBS, and imaging with a phase-contrast microscope. All steps were performed at RT.

\section{Alizarin Red staining}

Following osteocyte differentiation, cells were washed twice with PBS and fixed with 10\% neutral buffered formalin (Sigma) for $45 \mathrm{~min}$. Next, cells were washed twice with tap water and incubated with filtered Alizarin Red staining solution $(20 \mathrm{mg} / \mathrm{ml}$; Sigma) for $45 \mathrm{~min}$. After four washes with deionized water, PBS was added to the cells and images were obtained with a phase-contrast microscope. All steps were performed at RT.

\section{Immunofluorescence staining}

Cells were grown on imaging slides (Ibidi), washed three times with PBS, and fixed with $4 \%$ paraformaldehyde (Sigma) in PBS for $10 \mathrm{~min}$, followed by three washes using PBS. After permeabilization using 0.5\% Triton-X100 (Sigma) in PBS at $4{ }^{\circ} \mathrm{C}$ overnight and three washes with PBS, slides were blocked with $0.1 \%$ Triton-X-100 and $1 \%$ FBS in PBS for $1 \mathrm{~h}$ at room temperature. Incubation with primary antibodies was performed at $4{ }^{\circ} \mathrm{C}$ overnight. After three washes with PBS, slides were incubated with the species-corresponding secondary antibodies (Thermo Fisher Scientific) for $2 \mathrm{~h}$ at room temperature in the dark and washed three times with PBS afterwards. The samples were mounted with ProLong ${ }^{\oplus}$ Gold Antifade Reagent with DAPI (Thermo Fisher Scientific) on a coverslip and imaged with an Axio Observer.Z1 inverted epifluorescence microscope (Zeiss) equipped with a $\times 10 / 0.3$ Plan-NEOFLUAR objective (Zeiss). Primary antibodies were diluted 1:100 unless stated otherwise and secondary antibodies 1:1000 in blocking buffer. Primary antibodies that were used in this study are listed in Additional file 5: Table S2.

\section{Single molecule fluorescence in situ hybridization}

Cells were plated on imaging slides (Ibidi), fixed with 4\% paraformaldehyde, washed twice with PBS, and permeabilized with $70 \%$ ethanol overnight at $4{ }^{\circ} \mathrm{C}$. After two washes with PBS and pre-hybridization solution (10\% deionized formamide (Merck Millipore), 2x SSC), slides were incubated with $50 \mu \mathrm{l}$ hybridization solution containing $2 \mathrm{x}$ SSC, $10 \%$ formamide, $50 \mu$ g competitor E. coli tRNA
(Roche Diagnostics), 10\% dextran sulfate (VWR), $2 \mathrm{mg} / \mathrm{ml}$ BSA (UltraPure; Life Technologies), $10 \mathrm{mM}$ vanadylribonucleoside complex (NEB) and $1 \mathrm{ng} / \mu \mathrm{l}$ smFISH probes for $6 \mathrm{~h}$ at $37^{\circ} \mathrm{C}$. Afterwards, slides were washed twice with pre-hybridization solution at $37^{\circ} \mathrm{C}$, then twice with PBS with subsequent mounting with ProLong ${ }^{\circ}$ Gold Antifade Reagent with DAPI. Slides were imaged after $12 \mathrm{~h}$ when the mounting medium was fully cured on an Axio Observer.Z1 inverted epifluorescence microscope equipped with a $\times 63$ / 1.4 Plan-APOCHROMAT objective (Zeiss).

Probe Designer software by Biosearch Technologies was used to design probes for hNEAT1 $5^{\prime}$ segment and mNEAT1 middle segment, both conjugated to Quasar ${ }^{\circ} 670$ fluorescent dye. Sequences are listed in Additional file 5: Table S4. Probes for $h N E A T 1$ middle segment, $m N E A T 1$ $5^{\prime}$ segment, and MALAT1 (all conjugated to Quasar ${ }^{\circ} 570$ ) were pre-designed by Biosearch Technologies.

\section{Chemicals used for DNA binding}

Cells were treated either by $2 \mu \mathrm{M}$ actinomycin D (Thermo Fisher Scientific), $100 \mu \mathrm{g} / \mathrm{ml}$ Hoechst 33342 (Thermo Fisher Scientific), $50 \mu \mathrm{M} \alpha$-amanitin (Cayman Chemical), and $5 \mu \mathrm{M}$ mithramycin A (Abcam). Vincristine (Selleckchem), etoposide (Selleckchem), and flavopiridol (Biomol) were used at concentrations specified in Fig. 4f.

\section{Image analysis for paraspeckle counting}

The spot detection program Airlocalize [70] was used for paraspeckle quantification based on 3D image stacks with $6-\mu \mathrm{m}$ depth in $0.3-\mu \mathrm{m}$ increments as described previously [18]. The average number of paraspeckles was calculated from images containing 10-150 cells. Seven images were analyzed per condition and replicate.

\section{Quantification of nucleus size}

Quantification of nucleus size based on DAPI staining was done using the Fiji software. Per image, an intensity threshold was determined to mask the DAPI staining in a maximum projection of a 3D image stack with $6 \mu \mathrm{m}$ depth. The total DAPI area was divided by the number of cells per image to determine the average nucleus size per cell per image. The determination of nuclear size in single cells (Fig. $3 \mathrm{~b}$ ) was done by manually masking DAPI labeled nuclei and analyzing the nuclear area by the "Analyse Particles" function in Fiji.

\section{Flow cytometry analysis}

Surface marker staining was performed by washing dissociated cells with FACS buffer (1\% FBS in PBS), centrifugation, removal of supernatant and incubation with primary antibodies in FACS buffer for 30 min on ice. Next, after centrifugation and removal of supernatant, cells were incubated with species-corresponding secondary antibody for $30 \mathrm{~min}$ on ice, before washing and final resuspension 
in FACS buffer. A similar protocol was carried out with primary antibodies that were already conjugated to fluorophores.

Intracellular staining was performed according to instructions of the Inside Stain Kit (Miltenyi Biotec). Primary antibodies were incubated for $1 \mathrm{~h}$ at room temperature with $2.0 \times 10^{5}$ cells. Secondary antibodies were incubated for $30 \mathrm{~min}$ on ice. Cells were washed once with Inside Perm solution before resuspending them in FACS buffer for analysis.

Unconjugated primary antibodies were diluted 1:100 and secondary antibodies 1:1000 in FACS buffer. Samples were analyzed using the BD FACSAria III cell sorter (BD Biosciences), and data was processed using FlowJo software.

\section{RNA extraction and quantitative RT-PCR (RT-qPCR)}

RNA extraction was performed using the RNeasy Mini Kit (Qiagen) according to the manufacturer's instructions. Reverse transcription was performed using the Verso cDNA Synthesis Kit (Thermo Fisher Scientific) with 200 ng RNA per reaction. RT-qPCR was performed in 384-well plates using $5 \mu \mathrm{l}$ of SYBR Green PCR Master Mix (Thermo Fisher Scientific), $1 \mu \mathrm{l} c D N A$, and $1 \mu \mathrm{l}$ of $5 \mu \mathrm{M}$ primer forward and reverse mix in a $10 \mu \mathrm{l}$ reaction. PCR conditions were $2 \mathrm{~min}$ at $50^{\circ} \mathrm{C}$ and $10 \mathrm{~min}$ at $95^{\circ} \mathrm{C}$ followed by 40 cycles of $15 \mathrm{~s}$ at $95^{\circ} \mathrm{C}$ and $1 \mathrm{~min}$ at $60^{\circ} \mathrm{C}$. Relative expression levels were calculated using the Delta-Delta Ct method normalized with GAPDH. Statistical analysis was performed with the GraphPad Prism 7 software. RT-qPCR primers are listed in Additional file 5: Table S3.

\section{Generation of $\mathrm{NEAT1}^{-/-}$, NEAT1 $\triangle T H$, and NEAT1 ${ }^{\text {STOP }}$ hESCs} Generation of $N E A T 1^{-/-}$and NEAT1 $\triangle T H$ clones from hESCs was carried out according to a published protocol [71]. Briefly, the Protospacer adjacent Motif (PAM) sequence was identified using the crispr.mit.edu website. BbsI-digested pSpCas9(BB)-2A-GFP vector (Addgene plasmid ID: 48138) was ligated with annealed forward/ reverse guide RNA (gRNA) mix (1:250 dilution) using T4 ligase (NEB). $\mathrm{NEB}^{\circ} 5$-alpha competent $E$. coli bacteria (NEB) were inoculated with ligated plasmid and plated on agar plates. Bacteria colonies were propagated and plasmids were isolated using the GeneJET Plasmid MiniPrep Kit (LifeTechnologies) according to the manufacturer's instructions. Sanger sequencing was used to screen correct integrations. $1.0 \times 10^{6} \mathrm{hESCs}$ were nucleofected with $5 \mu \mathrm{g}$ of up- and downstream gRNA/ Cas9 plasmid mix using the P3 Primary Cell 4DNucleofector ${ }^{\ominus}$ Kit (Lonza) according to the manufacturer's instructions. Cells were plated 2 days later, and single clones were picked and analyzed for successful genomic deletion by PCR. NEAT1 ${ }^{S T O P}$ hESCs were generated by inserting a polyA stop cassette approximately
1500 base pairs after the NEAT1 transcription start site. $1.0 \times 10^{6} \mathrm{hESCs}$ were transfected with $4 \mu \mathrm{g}$ donor, and $2 \mu \mathrm{g}$ gRNA plasmid and clones were tested for successful integration by PCR. Guide RNAs and primers for PCRbased screening are listed in Additional file 5: Table S1.

\section{DNA extraction and polymerase chain reaction (PCR)}

Isolation of genomic DNA for screening of $\mathrm{KO}$ clones after transfection of CRISPR/Cas9 was performed using $30 \mu \mathrm{l}$ QuickExtract ${ }^{\text {tm }}$ (Biozym) according to the manufacturer's instructions. PCR was performed using Q5 Polymerase mastermix (NEB) with 100 ng DNA.

\section{Supplementary information}

Supplementary information accompanies this paper at https://doi.org/10. 1186/s12915-020-00770-y.

Additional file 1: Figure S1. Related to Figs. 1 and 2, characterization of germ layer progenitors and differentiated cells. a Analysis of mesoderm differentiation towards mesenchymal stem cells (MSCs) showing the expression of characteristic markers CD73 and CD90 [72]. bd Differentiation towards definitive endoderm showing the upregulation of CXCR4, EPCAM and CD117 cell surface markers (b) and a cohort of characteristic markers as well as the downregulation of pluripotency genes by RT-qPCR (c), and the expression of eGFP integrated in NKX2.1 which marks the formation of human lung progenitors [57] (d). Scale bar: $10 \mu \mathrm{m}$. e, $\mathbf{f}$ Representative immunocytochemistry images of NSCs showing the expression of characteristic markers PAX6, SOX1 and NESTIN on day 21 of NSC differentiation (e), and the cortical neuron progenitor markers FOXG1 and PAX6 (f) [68]. Scale bar: $50 \mu \mathrm{m}$. g, h Oil Red O (g) and Alizarin Red (h) staining of human MSCs differentiated to adipocytes and osteocytes, respectively. Scale bar: $500 \mu \mathrm{m}$. i, j Time course RT-qPCR analysis of representative pluripotency, mesoderm and cardiac markers during lateral mesoderm differentiation to cardiomyocytes (i) [60], and of representative intermediate mesoderm and nephron progenitor markers during nephron differentiation (j) [61]. k Representative images showing the expression of characteristic nephron progenitor markers $\mathrm{CDH} 5$ and WT1 at day 14 of differentiation. Scale bar: $50 \mu \mathrm{m}$. I RT-qPCR analysis of representative pluripotency, definitive endoderm and hepatocyte markers during differentiation to hepatocytes at day 16 [64]. m-o RT-qPCR analysis of representative pluripotency, motor neuron, glial and cortical markers following differentiation to motor neurons $(\mathbf{m})$, astrocytes $(\mathbf{n})$ and cortical neurons (o). $n=2$ independent experiments $(n=3$ in $\mathbf{i}, \mathbf{I})$, error bars represent standard deviation, cells in different passages were used for replicates.

Additional file 2: Figure S2. Related to Fig. 2, quantification of paraspeckles. a, b Representative images of NEAT1_2 (red) in cells representing tissue progenitors (a), and terminally differentiated cells (b). c The number of paraspeckles per cell in progenitors and differentiated cell types used to calculate the average number of paraspeckles in Fig. $2 \mathrm{~b}$. Each dot represents the average of one microscopic image displaying $10-150$ cells. $n=3$ independent replicates using cells of different passages were analyzed with 5-7 images per replicate. Changes in number of paraspeckles are statistically significant for all cell types compared to human ESCs $\left(p<0.0001\right.$, unpaired t-test; $\left.{ }^{* * *} p<0.001\right)$. d Number of paraspeckles in neural stem cells (NSCs) in passage (P) 1, 3 and 5 representing respectively differentiation day 21, 35 and 49 . Counting as in $\mathbf{c} . n=2$ independent differentiation experiments. n.s. $=$ not significant. e Correlation of differentiation time as specified in the method section and averaged number of paraspeckles per cell type. $\mathbf{f}$ Representative images of NEAT1_2 (red) in mouse ESCs and primary cardiomyocytes, hepatocytes, MSCs and astrocytes, next to same cell types from the human. $\mathbf{g}$ Correlation of NEAT1_2 total intensity and the number of paraspeckles per cell in representative human and mouse cell types. Each point represents a microscopic image. h RT-qPCR of NEAT1_2 in 19 cell 
types and correlation with averaged number of paraspeckles per cell indicated in Fig. 2b. RNA was obtained from 2 - 4 independent RNA differentiation experiments of cells in different passages. $\mathbf{i}$ Time-course RT-qPCR analysis of endogenous transcription of pluripotency factors OCT4, SOX2 and NANOG during reprogramming of human neonatal fibroblasts. $n=2$ independent reprogramming experiments. $\mathbf{j}, \mathbf{k}$ Representative brightfield (j) and NEAT1_2 (k) images taken during fibroblast reprogramming. $n=2$ independent reprogramming experiments using cells of different passages were analyzed with 7 images per replicate; nascent iPSC colonies are marked with white circles. Error bars represent standard deviation. DAPI staining in blue; scale bar is $10 \mu \mathrm{m}$ in smFISH images and $50 \mu \mathrm{m}$ in brightfield images. $r$ in $\mathbf{e}, \mathbf{g}, \mathbf{h}$ represents the Pearson's correlation coefficient.

Additional file 3: Figure S3. Related to Fig. 4, characterization of IncRNA foci after treatment by Actinomycin D. a Representative images of NEAT1_2 smFISH after treatment of human ESC derived astrocytes, definitive endoderm cells, NSCs and primary neonatal fibroblasts by $2 \mu \mathrm{M}$ ActD. $\mathbf{b}$ Immunocytochemistry of nucleolar protein fibrillarin (FBL) and paraspeckle proteins SFPQ and NONO in untreated trophoblast progenitors and after treatment by $2 \mu \mathrm{M}$ ActD for $1 \mathrm{~h}$. c Representative immunocytochemistry images of $\mathrm{Y}-\mathrm{H} 2 \mathrm{AX}$ foci indicating DNA doublestrand breaks in trophoblast progenitors and after addition of small DNA binding molecules. Quantification in Fig. 4e. Concentrations as in Fig. 4a, b. d A table indicating the potential of small molecules used in this study to bind DNA, to inhibit transcription and to disintegrate paraspeckles. e, $\mathbf{f}$ Representative images (e) and quantification (f) of MALAT1 smFISH in human trophoblast progenitors treated with ActD as above. $n=2$ independent replicates with 7 images per replicate. Dashed lines in $\mathbf{a}$ and $\mathbf{f}$ show the locations of the borders of the nuclei. Scale bar is $10 \mu \mathrm{m}$.

Additional file 4: Figure S4. Related to Fig. 5, characterization of NEAT1-manipulated cells. a RT-qPCR of pluripotency and differentiation markers of undifferentiated NEAT1 ${ }^{-1}$, NEAT1 ${ }^{\text {STOP }}$ and NEAT1 $\triangle T H$ hESC clones. b, c Flow cytometry analysis of pluripotency surface markers TRA1-60 and SSEA5 after 2 days of spontaneous differentiation of WT, NEATIDTH and NEAT1 ${ }^{-1-}$ hESCs. d RT-QPCR time course analysis of pluripotency and neural marker genes during differentiation towards neural rosettes which appeared around day 12 of the differentiation towards NSCs. Same cell lines as in $\mathbf{b}, \mathbf{c}$. e-g RT-qPCR analysis of NEAT1 $\triangle p A$ hESC clones differentiated to lateral mesoderm $(\mathbf{e})$, definitive endoderm $(\mathbf{f})$ and neuroectoderm by 4 days differentiation of NSCs $(\mathbf{g})$. h-k Representative histograms and quantification of flow cytometry analysis for pluripotency markers in pluripotent $(\mathbf{h}, \mathbf{j})$ NEAT1 ${ }^{\text {STOP }}$ hESCs and after 3 days of spontaneous differentiation $(\mathbf{i}, \mathbf{k})$. Forward and side scatter gating was employed to gate out debris and cell clumps. $\mathrm{n}$ (\# of experiments / \# of clones) $=3$ / 2 in $\mathbf{a}, 1 / 3$ in $\mathbf{c}, \mathbf{e}, \mathbf{f}, 2 / 3$ in $\mathbf{d}, \mathbf{g}$ and $2 / 2$ in $\mathbf{j}, \mathbf{k}$. Error bars represent standard deviation.

Additional file 5: List of primers, smFISH probes and antibodies. Table S1. Sequence and genomic location of gRNAs and primers used for the generation of CRISPR lines. Table S2. List of antibodies. Table S3. List of RT-qPCR primer sequences. Table S4. List of sequences of smFISH probes.

Additional file 6: Raw data for graphs with $N<6$. Table 55 . Raw data for Fig. 1b-d, f. Figure S1c, i, j, I-o, Figure S2h, i. Table S6. Raw data for Fig. 5d, e, Figure S4a, d-g. Table S7. Raw data for Fig. 5g, i, Figure S4c, j, k.

\section{Acknowledgements}

We are grateful for murine MSCs provided by Dr. Michael Rosemann (Helmholtz Zentrum München) and for vincristine and etoposide that was provided by Dr. Thomas Grünewald (LMU). We would like to thank Dr. Sabrina Desbordes for sharing protocols for hepatocyte differentiation and providing antibodies for their characterization. We would also like to thank Dr. Friederike Matheus for providing the neural crest cells and Dr. Daniela Vogt-Weisenhorn and Dr. Petra Dirscherl for providing primary murine astrocytes.

\section{Authors' contributions}

M.G. and M.D. designed the study, and M.G., S.I., E.R., T.G., C.O., A.P., D.T., and A.C.O. performed all experiments. G.W. contributed to project's supervision. M.G. and M.D. wrote the paper. All authors read and approved the final manuscript.

\section{Funding}

Markus Grosch was funded by the HELENA graduate school. Additional support was provided by the UHU cooperation seed funding.

\section{Availability of data and materials}

The datasets supporting the conclusions of this article are included within the article (and its additional files). Raw data for experiments with $N<6$ can be found in Additional file 6: supplementary Tables 5-7.

\section{Ethics approval and consent to participate}

Mouse keeping was performed at the central facilities at the Helmholtz Center Munich in accordance with the German animal welfare legislation and guidelines of the Society of Laboratory Animals (GV-SOLAS) and of the Federation of Laboratory Animal Science Associations (FELASA)

\section{Consent for publication}

Not applicable.

\section{Competing interests}

M.D. and M.G. are named on a patent application related to the content of the manuscript.

\section{Author details}

1 Institute of Stem Cell Research (ISF), Helmholtz Zentrum München, Neuherberg, Germany. ${ }^{2}$ Institute of Stem Cell Research (ISF), iPSC Core Facility, Helmholtz Zentrum München, Neuherberg, Germany.

${ }^{3}$ Comprehensive Pneumology Center (CPC), Helmholtz Zentrum München, Member of the German Center for Lung Research (DZL), Munich, Germany. ${ }^{4}$ Institute of Biological and Medical Imaging (IBMI), Helmholtz Zentrum München, Neuherberg, Germany.

Received: 30 January 2020 Accepted: 16 March 2020

Published online: 22 April 2020

\section{References}

1. Hezroni H, Koppstein D, Schwartz MG, Avrutin A, Bartel DP, Ulitsky I. Principles of long noncoding RNA evolution derived from direct comparison of transcriptomes in 17 species. Cell Rep. 2015;11(7):1110-22.

2. Tang Y, Wang J, Lian Y, Fan C, Zhang P, Wu Y, et al. Linking long noncoding RNAs and SWI/SNF complexes to chromatin remodeling in cancer. Mol Cancer. 2017;16(1):42.

3. Achour C, Aguilo F. Long non-coding RNA and Polycomb: an intricate partnership in cancer biology. Front Biosci (Landmark Ed). 2018;23:2106-32.

4. Banani SF, Lee HO, Hyman AA, Rosen MK. Biomolecular condensates: organizers of cellular biochemistry. Nat Rev Mol Cell Biol. 2017;18(5):285-98.

5. He R-Z, Luo D-X, Mo Y-Y. Emerging roles of IncRNAs in the posttranscriptional regulation in cancer. Genes Dis. 2019:6(1):6-15.

6. Naganuma T, Nakagawa S, Tanigawa A, Sasaki YF, Goshima N, Hirose T. Alternative 3 '-end processing of long noncoding RNA initiates construction of nuclear paraspeckles. EMBO J. 2012;31(20):4020-34.

7. Kawaguchi T, Tanigawa A, Naganuma T, Ohkawa Y, Souquere S, Pierron G, et al. SWI/SNF chromatin-remodeling complexes function in noncoding RNA-dependent assembly of nuclear bodies. Proc Natl Acad Sci U S A. 2015; 112(14):4304-9.

8. Romero-Barrios N, Legascue MF, Benhamed M, Ariel F, Crespi M. Splicing regulation by long noncoding RNAs. Nucleic Acids Res. 2018;46(5):2169-84.

9. Fox AH, Nakagawa S, Hirose T, Bond CS. Paraspeckles: where long noncoding RNA meets phase separation. Trends Biochem Sci. 2018;43(2): 124-35.

10. Chujo T, Yamazaki T, Hirose T. Architectural RNAs (arcRNAs): a class of long noncoding RNAs that function as the scaffold of nuclear bodies. Biochim Biophys Acta. 2016;1859(1):139-46.

11. Rot G, Wang Z, Huppertz I, Modic M, Lenče T, Hallegger M, et al. Highresolution RNA maps suggest common principles of splicing and polyadenylation regulation by TDP-43. Cell Rep. 2017;19(5):1056-67.

12. Li Y, Syed J, Sugiyama H. RNA-DNA triplex formation by long noncoding RNAs. Cell Chem Biol. 2016;23(11):1325-33.

13. Sentürk Cetin N, Kuo C-C, Ribarska T, Li R, Costa IG, Grummt I. Isolation and genome-wide characterization of cellular DNA:RNA triplex structures. Nucleic Acids Res. 2019;47(5):2306-21. 
14. West JA, Davis CP, Sunwoo H, Simon MD, Sadreyev RI, Wang Pl, et al. The long noncoding RNAs NEAT1 and MALAT1 bind active chromatin sites. Mol Cell. 2014:55(5):791-802.

15. Zhang $X$, Zhang SC, Sun D, Hu J, Wali A, Pass $H$, et al. New insight into the molecular mechanisms of the biological effects of DNA minor groove binders. PLoS One. 2011;6(10):e25822.

16. Chen H, Liu X, Patel DJ. DNA bending and unwinding associated with actinomycin D antibiotics bound to partially overlapping sites on DNA. J Mol Biol. 1996;258(3):457-79.

17. Dixon JR, Jung I, Selvaraj S, Shen Y, Antosiewicz-Bourget JE, Lee AY, et al. Chromatin architecture reorganization during stem cell differentiation. Nature. 2015;518(7539):331-6.

18. Modic M, Grosch M, Rot G, Schirge S, Lepko T, Yamazaki T, et al. Crossregulation between TDP-43 and paraspeckles promotes pluripotencydifferentiation transition. Mol Cell. 2019;74(5):951. 965.e13.

19. Fox AH, Lamond Al. Paraspeckles. Cold Spring Harb Perspect Biol. 2010;2(7): a000687.

20. Nakagawa S, Naganuma T, Shioi G, Hirose T. Paraspeckles are subpopulation-specific nuclear bodies that are not essential in mice. J Cell Biol. 2011;193(1):31-9.

21. Hupalowska A, Jedrusik A, Zhu M, Bedford MT, Glover DM, Zernicka-Goetz M. CARM1 and paraspeckles regulate pre-implantation mouse embryo development. Cell. 2018;175(7):1902-1916.e13.

22. Sun $\mathrm{Q}$, Hao Q, Prasanth KV. Nuclear long noncoding RNAs: key regulators of gene expression. Trends Genet. 2018;34(2):142-57.

23. Cabili MN, Dunagin MC, McClanahan PD, Biaesch A, Padovan-Merhar O, Regev A, et al. Localization and abundance analysis of human IncRNAs at single-cell and single-molecule resolution. Genome Biol. 2015;16(1):20.

24. Bronner ME, LeDouarin NM. Development and evolution of the neural crest: an overview. Dev Biol. 2012;366(1):2-9.

25. Bajpai R, Chen DA, Rada-Iglesias A, Zhang J, Xiong Y, Helms J, et al. CHD7 cooperates with PBAF to control multipotent neural crest formation. Nature. 2010;463(7283):958-62.

26. Krendl C, Shaposhnikov D, Rishko V, Ori C, Ziegenhain C, Sass S, et al. GATA2/3-TFAP2A/C transcription factor network couples human pluripotent stem cell differentiation to trophectoderm with repression of pluripotency. Proc Natl Acad Sci U S A. 2017;114(45):E9579-88.

27. Chen $\mathrm{L}-\mathrm{L}$, Carmichael GG. Altered nuclear retention of mRNAs containing inverted repeats in human embryonic stem cells: functional role of a nuclear noncoding RNA. Mol Cell. 2009;35(4):467-78.

28. Weissman IL, Anderson DJ, Gage F. Stem and progenitor cells: origins, phenotypes, lineage commitments, and transdifferentiations. Annu Rev Cell Dev Biol. 2001;17(1):387-403.

29. Wu H, Sun YE. Epigenetic regulation of stem cell differentiation. Pediatr Res, 2006;59(4):21-5

30. Chen T, Dent SYR. Chromatin modifiers and remodellers: regulators of cellular differentiation. Nat Rev Genet. 2014;15(2):93-106.

31. Edens $\sqcup$, , White $K H$, Jevtic $P$, Li X, Levy DL. Nuclear size regulation: from single cells to development and disease. Trends Cell Biol. 2013;23(4):151-9.

32. Funayama R, Ishikawa F. Cellular senescence and chromatin structure. Chromosoma. 2007;116(5):431-40.

33. Kuo C-C, Hänzelmann S, Sentürk Cetin N, Frank S, Zajzon B, Derks J-P, et al. Detection of RNA-DNA binding sites in long noncoding RNAs. Nucleic Acids Res. 2019;47(6):e32.

34. Fox AH, Lam YW, Leung AKL, Lyon CE, Andersen J, Mann M, et al, Paraspeckles: a novel nuclear domain. Curr Biol. 2002;12(1):13-25.

35. Fox AH, Bond CS, Lamond Al. P54nrb forms a heterodimer with PSP1 that localizes to paraspeckles in an RNA-dependent manner. Mol Biol Cell. 2005; 16(11):5304-15.

36. Sastry M, Fiala R, Patel D. Solution structure of mithramycin dimers bound to partially overlapping sites on DNA. J Mol Biol. 1995;251(5):674-89.

37. Sriram $M$, van der Marel GA, Roelen $\mathrm{HL}$, van Boom JH, Wang $\mathrm{AH}$. Conformation of B-DNA containing O6-ethyl-G-C base pairs stabilized by minor groove binding drugs: molecular structure of d(CGC[e6G]AATTCGCG complexed with Hoechst 33258 or Hoechst 33342. EMBO J 1992;11(1):225-232

38. Clemson CM, Hutchinson JN, Sara SA, Ensminger AW, Fox AH, Chess A, et al. An architectural role for a nuclear noncoding RNA: NEAT1 RNA is essential for the structure of paraspeckles. Mol Cell. 2009;33(6):717-26.

39. Yamazaki T, Souquere S, Chujo T, Kobelke S, Chong YS, Fox AH, et al. Functional domains of NEAT1 architectural IncRNA induce paraspeckle assembly through phase separation. Mol Cell. 2018;70(6):1038-1053.e7.
40. Robles SJ, Adami GR. Agents that cause DNA double strand breaks lead to p16INK4a enrichment and the premature senescence of normal fibroblasts. Oncogene. 1998;16(9):1113-23.

41. Kuo LJ, Yang L-X. Gamma-H2AX - a novel biomarker for DNA double-strand breaks. In Vivo. 2008;22(3):305-9.

42. Wagner MJ, Livingston JA, Patel SR, Benjamin RS. Chemotherapy for bone sarcoma in adults. J Oncol Pract. 2016;12(3):208-16.

43. Stanton RA, Gernert KM, Nettles JH, Aneja R. Drugs that target dynamic microtubules: a new molecular perspective. Med Res Rev. 2011;31(3):443-81.

44. Nitiss JL. Targeting DNA topoisomerase II in cancer chemotherapy. Nat Rev Cancer. 2009;9(5):338-50

45. Chen R, Keating MJ, Gandhi V, Plunkett W. Transcription inhibition by flavopiridol: mechanism of chronic lymphocytic leukemia cell death. Blood. 2005;106(7):2513-9.

46. Bible KC, Bible RH, Kottke TJ, Svingen PA, Xu K, Pang YP, et al. Flavopiridol binds to duplex DNA. Cancer Res. 2000;60(9):2419-28.

47. Wu C-C, Li T-K, Farh L, Lin L-Y, Lin T-S, Yu Y-J, et al. Structural basis of type II topoisomerase inhibition by the anticancer drug etoposide. Science. 2011; 333(6041):459-62

48. Derrien T, Johnson R, Bussotti G, Tanzer A, Djebali S, Tilgner $H$, et al. The GENCODE v7 catalog of human long noncoding RNAs: analysis of their gene structure, evolution, and expression. Genome Res. 2012;22(9):1775-89.

49. Sasaki YTF, Ideue T, Sano M, Mituyama T, Hirose T. MENepsilon/beta noncoding RNAs are essential for structural integrity of nuclear paraspeckles. Proc Natl Acad Sci U S A. 2009;106(8):2525-30.

50. West JA, Mito M, Kurosaka S, Takumi T, Tanegashima C, Chujo T, et al. Structural, super-resolution microscopy analysis of paraspeckle nuclear body organization. J Cell Biol. 2016;214(7):817-30.

51. Wang Y, Hu S-B, Wang M-R, Yao R-W, Wu D, Yang L, et al. Genome-wide screening of NEAT1 regulators reveals cross-regulation between paraspeckles and mitochondria. Nat Cell Biol. 2018;20(10):1145-58.

52. Dong P, Xiong Y, Yue J, Hanley SJB, Kobayashi N, Todo Y, et al. Long noncoding RNA NEAT1: a novel target for diagnosis and therapy in human tumors. Front Genet. 2018;15:9. [cited 2019 Sep 25]. Available from: https:// www.ncbi.nlm.nih.gov/pmc/articles/PMC6196292/.

53. Jevtić $P$, Levy DL. Mechanisms of nuclear size regulation in model systems and cancer. Adv Exp Med Biol. 2014;773:537-69.

54. He X, Ou C, Xiao Y, Han Q, Li H, Zhou S. LncRNAs: key players and novel insights into diabetes mellitus. Oncotarget. 2017;8(41):71325-41.

55. Huarte M. The emerging role of IncRNAs in cancer. Nat Med. 2015;21(11): 1253-61.

56. Aznab M, Hematti M. Evaluation of clinical process in osteosarcoma patients treated with chemotherapy including cisplatin, adriamycin, ifosfamide, and etoposide and determination of the treatment sequels in a long-term 11year follow-up. J Cancer Res Ther. 2017;13(2):291-6.

57. Olmer R, Dahlmann J, Merkert S, Baus S, Göhring G, Martin U. Generation of a NKX2.1 knock-in reporter cell line from human induced pluripotent stem cells (MHHi006-A-2). Stem Cell Res. 2019;39:101492.

58. Kunze C, Börner K, Kienle E, Orschmann T, Rusha E, Schneider M, et al, Synthetic AAV/CRISPR vectors for blocking HIV-1 expression in persistently infected astrocytes. Glia. 2018;66(2):413-27.

59. Matheus F, Rusha E, Rehimi R, Molitor L, Pertek A, Modic M, et al. Pathological ASXL1 mutations and protein variants impair neural crest development. Stem Cell Rep. 2019;12(5):861-8.

60. Lian X, Zhang J, Azarin SM, Zhu K, Hazeltine LB, Bao X, et al. Directed cardiomyocyte differentiation from human pluripotent stem cells by modulating Wnt/ $\beta$-catenin signaling under fully defined conditions. Nat Protoc. 2013;8(1):162-75.

61. Morizane R, Bonventre JV. Generation of nephron progenitor cells and kidney organoids from human pluripotent stem cells. Nat Protoc. 2017;12(1): 195-207.

62. Kajiwara M, Aoi T, Okita K, Takahashi R, Inoue H, Takayama N, et al. Donordependent variations in hepatic differentiation from human-induced pluripotent stem cells. PNAS. 2012;109(31):12538-43.

63. Konishi S, Gotoh S, Tateishi K, Yamamoto Y, Korogi Y, Nagasaki T, et al Directed induction of functional multi-ciliated cells in proximal airway epithelial spheroids from human pluripotent stem cells. Stem Cell Rep. 2016:6(1):18-25

64. Carpentier A, Tesfaye A, Chu V, Nimgaonkar I, Zhang F, Lee SB, et al. Engrafted human stem cell-derived hepatocytes establish an infectious HCV murine model. J Clin Invest. 2014;124(11):4953-64. 
65. Reinhardt P, Glatza M, Hemmer K, Tsytsyura Y, Thiel CS, Höing S, et al. Derivation and expansion using only small molecules of human neural progenitors for neurodegenerative disease modeling. PLoS One. 2013;8(3): e59252.

66. Shaltouki A, Peng J, Liu Q, Rao MS, Zeng X. Efficient generation of astrocytes from human pluripotent stem cells in defined conditions. Stem Cells. 2013;31(5):941-52.

67. Qu Q, Li D, Louis KR, Li X, Yang H, Sun Q, et al. High-efficiency motor neuron differentiation from human pluripotent stem cells and the function of Islet-1. Nat Commun. 2014;5:3449.

68. Shi Y, Kirwan P, Livesey FJ. Directed differentiation of human pluripotent stem cells to cerebral cortex neurons and neural networks. Nat Protoc. 2012; 7(10):1836-46.

69. Gonçalves LA, Vigário AM, Penha-Gonçalves C. Improved isolation of murine hepatocytes for in vitro malaria liver stage studies. Malar J. 2007;6(1):169.

70. Trcek T, Lionnet T, Shroff H, Lehmann R. mRNA quantification using singlemolecule FISH in Drosophila embryos. Nat Protoc. 2017;12(7):1326-48,

71. Ran FA, Hsu PD, Wright J, Agarwala V, Scott DA, Zhang F. Genome engineering using the CRISPR-Cas9 system. Nat Protoc. 2013;8(11):2281-308

72. L Ramos T, Sánchez-Abarca LI, Muntión S, Preciado S, Puig N, López-Ruano $\mathrm{G}$, et al. MSC surface markers (CD44, CD73, and CD90) can identify human MSC-derived extracellular vesicles by conventional flow cytometry. Cell Commun Signal. 2016;14:2.

\section{Publisher's Note}

Springer Nature remains neutral with regard to jurisdictional claims in published maps and institutional affiliations.

Ready to submit your research? Choose BMC and benefit from:

- fast, convenient online submission

- thorough peer review by experienced researchers in your field

- rapid publication on acceptance

- support for research data, including large and complex data types

- gold Open Access which fosters wider collaboration and increased citations

- maximum visibility for your research: over $100 \mathrm{M}$ website views per year

At $\mathrm{BMC}$, research is always in progress.

Learn more biomedcentral.com/submissions 